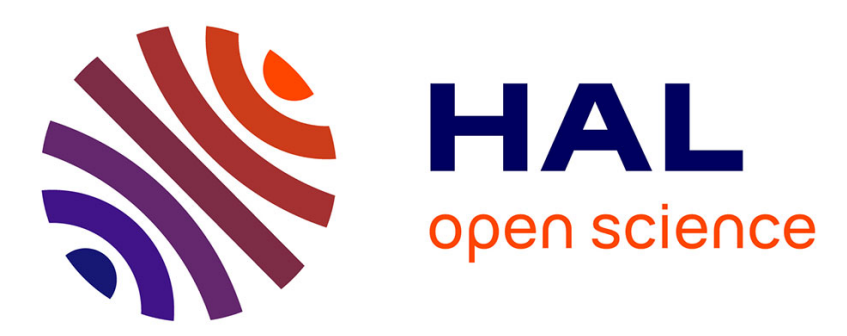

\title{
Identification of an endocannabinoid gut-brain vagal mechanism controlling food reward and energy homeostasis
}

Chloe Berland, Julien Castel, Romano Terrasi, Enrica Montalban, Ewout Foppen, Claire Martin, Giulio G. Muccioli, Serge Luquet, Giuseppe Gangarossa

\section{To cite this version:}

Chloe Berland, Julien Castel, Romano Terrasi, Enrica Montalban, Ewout Foppen, et al.. Identification of an endocannabinoid gut-brain vagal mechanism controlling food reward and energy homeostasis. Molecular Psychiatry, 2022, 10.1038/s41380-021-01428-z . hal-03677213v2

\section{HAL Id: hal-03677213 \\ https://cnrs.hal.science/hal-03677213v2}

Submitted on 15 Nov 2022

HAL is a multi-disciplinary open access archive for the deposit and dissemination of scientific research documents, whether they are published or not. The documents may come from teaching and research institutions in France or abroad, or from public or private research centers.
L'archive ouverte pluridisciplinaire HAL, est destinée au dépôt et à la diffusion de documents scientifiques de niveau recherche, publiés ou non, émanant des établissements d'enseignement et de recherche français ou étrangers, des laboratoires publics ou privés. 


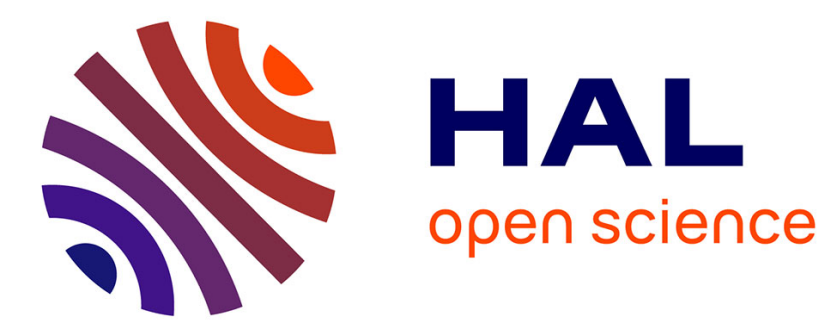

\title{
Identification of an endocannabinoid gut-brain vagal mechanism controlling food reward and energy homeostasis
}

\author{
Chloé Berland, Julien Castel, Enrica Montalban, Ewout Foppen, Claire \\ Martin, Giulio G Muccioli, Serge Luquet, Giuseppe Gangarossa
}

\section{To cite this version:}

Chloé Berland, Julien Castel, Enrica Montalban, Ewout Foppen, Claire Martin, et al.. Identification of an endocannabinoid gut-brain vagal mechanism controlling food reward and energy homeostasis. 2021. hal-03372058

\section{HAL Id: hal-03372058 https://hal.archives-ouvertes.fr/hal-03372058}

Preprint submitted on 9 Oct 2021

HAL is a multi-disciplinary open access archive for the deposit and dissemination of scientific research documents, whether they are published or not. The documents may come from teaching and research institutions in France or abroad, or from public or private research centers.
L'archive ouverte pluridisciplinaire HAL, est destinée au dépôt et à la diffusion de documents scientifiques de niveau recherche, publiés ou non, émanant des établissements d'enseignement et de recherche français ou étrangers, des laboratoires publics ou privés. 


\section{1}

24 Key words: binge eating, dopamine, 2-AG, vagus nerve, striatum, reward, 25 metabolism

\section{food reward and energy homeostasis}

\author{
Chloé Berland ${ }^{1}$, Julien Castel ${ }^{1}$, Enrica Montalban ${ }^{1}$, Ewout Foppen ${ }^{1}$, Claire Martin¹, \\ Giulio G. Muccioli ${ }^{2}$, Serge Luquet ${ }^{1}$, Giuseppe Gangarossa ${ }^{1}$
}

${ }^{1}$ Université de Paris, BFA, UMR 8251, CNRS, F-75013 Paris, France

${ }^{2}$ Bioanalysis and Pharmacology of Bioactive Lipids Research Group, Louvain Drug Research Institute, Université catholique de Louvain, 1200 Brussels, Belgium

\section{Correspondence to: giuseppe.gangarossa@u-paris.fr (GG, @PeppeGanga)}

\section{Identification of an endocannabinoid gut-brain vagal mechanism controlling}

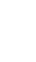




\section{Abstract (234)}

27 The regulation of food intake, a sine qua non requirement for survival, thoroughly shapes feeding and energy balance by integrating both homeostatic and hedonic values of food. Unfortunately, the widespread access to palatable food has led to the development of feeding habits that are independent from metabolic needs. Among these, binge eating $(\mathrm{BE})$ is characterized by uncontrolled voracious eating. While reward deficit seems to be a major contributor of $\mathrm{BE}$, the physiological and molecular underpinnings of $\mathrm{BE}$ establishment remain elusive. Here, we combined a physiologically relevant $\mathrm{BE}$ mouse model with multiscale in vivo integrative approaches to explore the functional connection between the gut-brain axis and the reward and homeostatic brain structures.

37 Our results show that BE elicits compensatory adaptations requiring the gut-to-brain axis which, through the vagus nerve, relies on the permissive actions of peripheral endocannabinoids (eCBs) signaling. Selective inhibition of peripheral CB1 receptors resulted in a vagus-dependent increased hypothalamic activity, modified metabolic efficiency, and dampened activity of mesolimbic dopamine circuit, altogether leading

42 to the suppression of palatable eating. We provide compelling evidence for a yet 43 unappreciated physiological integrative mechanism by which variations of peripheral 44 eCBs control the activity of the vagus nerve, thereby in turn gating the additive responses of both homeostatic and hedonic brain circuits which govern homeostatic and reward-driven feeding.

47 In conclusion, we reveal that vagus-mediated eCBs/CB1R functions represent an 48 interesting and innovative target to modulate energy balance and food-reward 49 disorders. 
51

52

53

54

55

56

57

58

59

60

61

62

63

64

65

66

67

68

69

70

71

72

73

74

\section{Introduction}

Feeding is a complex and highly conserved process whose orchestration results from the dynamic integration of homeostatic and hedonic signals (Lutter and Nestler, 2009; Rossi and Stuber, 2018; Saper et al., 2002). While the firsts can be broadly defined as key regulators of food intake to ensure optimal energy balance, the seconds mainly relate to the reinforcing properties of sensory stimuli (perception, cues, taste, odors) and reward-associated features of feeding. The homeostatic and hedonic components of feeding have been respectively attributed to the hypothalamic and the reward systems (Berthoud et al., 2017). However, despite the well-accepted recognition that both feeding components are tightly and functionally interconnected (Berthoud et al., 2017), they have usually been investigated as isolated systems: homeostatic feeding vs hedonic feeding (Rossi and Stuber, 2018). In addition, the counterpointing central vs peripheral regulations of feeding add a supplemental degree of complexity in the identification of integrative regulatory mechanisms (Coll et al., 2007; Lenard and Berthoud, 2008).

While energy homeostasis refers to negative feedback mechanisms maintaining the body weight at set-points, the combination of both homeostatic and hedonic components of feeding leads to the establishment of feed-forward mechanisms of physiological adaptations. Feed-forward adaptation, also known as allostasis (stability through changes), is critical in shaping energy balance and metabolic efficiency (McEwen and Wingfield, 2003) but also in contributing to rewardassociated events (George et al., 2012; Keramati and Gutkin, 2014). Indeed, the facilitated access to and the widespread consumption of palatable diets have profoundly altered the delicate allostatic integration of homeostatic and hedonic signals, thereby leading to the development of metabolic disorders. This is particularly evident in food reward-driven dysfunctions such as binge eating (BE), where the uncontrolled feeding perfectly recapitulates the efforts for an organism to adapt its homeostatic processes to the hedonic aspects of feeding. In fact, shortand/or long-term consumption of energy-rich palatable diets promotes dopamine (DA) release from the ventral tegmental area (VTA) of the reward system (Rada et al., 2005; Small et al., 2003; Wise, 2004) as well as functional adaptations within the hypothalamus (Beutler et al., 2020; Linehan et al., 2020; Mazier et al., 2019; Rossi et al., 2019; Wei et al., 2015). Integrative allostatic mechanisms in the hypothalamus 
84 and reward systems play a major role in ensuring metabolic efficiency and 85 adaptation. Beyond these two core processors of feeding, recent reports have

86

87 mechanistically demonstrated that the gut-brain vagal axis, beside sensing interoceptive signals and influencing feeding and energy homeostasis (Bai et al., 2019; Kaelberer et al., 2018; de Lartigue, 2016), is also a major modulator of the reward system (Fernandes et al., 2020; Han et al., 2016, 2018; Hankir et al., 2017; Malbert et al., 2019; Tellez et al., 2013). However, the physiological processes by which the gut-to-brain axis modulates reward feeding remain still unclear. Emerging evidence strongly suggests that, besides a plethora of peripheral hormones (i.e. ghrelin, leptin, GLP-1, CCK) (Gribble and Reimann, 2019), peripheral endocannabinoids (eCBs) may be fundamental players in the regulation of feeding and metabolic efficiency (Argueta and DiPatrizio, 2017; Capasso et al., 2018; DiPatrizio et al., 2013; Gómez et al., 2002; Izzo et al., 2009). Indeed, eating disorders-associated alterations in peripheral eCBs have been reported in obese and BE patients (Monteleone et al., 2016, 2017, 2005; Quarta et al., 2011) as well as in diet-induced obese rodents (Argueta and DiPatrizio, 2017; Kuipers et al., 2018). However, whether and how peripheral eCBs play a permissive role in both guiding reward-based feeding behaviors and buffering the allostatic regulation of energy balance remain still unexplored.

To tackle this question, we took advantage of a physiologically relevant binge eating-like mouse paradigm which, by promoting anticipatory and escalated consummatory food responses, triggers reward-driven behavioral, molecular and homeostatic adaptations. Binge eating, which elicited DA-dependent molecular modifications in the dopaminoceptive and reward-related structures, the dorsal striatum (DS) and the nucleus accumbens (NAc), revealed a yet unappreciated integrative gut-to-brain orchestration requiring the modulatory actions of peripheral eCBs. In particular, we show that binge eating requires an orchestrated dialog between peripheral eCBs and both central hypothalamic and VTA structures through the gut-brain vagal axis, thus modulating both energy balance and reward-like events. 


\section{$114 \quad$ Material and methods}

\section{Animals}

117 All experiments using animals were approved by the Animal Care Committee of the 118 Université de Paris (CEB-25-2016). 8-10 weeks old male C57BI/6J mice (20-30 119 grams, Janvier, Le Genest St Isle, France) were single-housed one week prior to any 120 experimentation in a room maintained at $22+/-1^{\circ} \mathrm{C}$, with light period from 7 AM to 7 121 PM. Regular chow diet (3 $438 \mathrm{kcal} / \mathrm{kg}$, protein $19 \%$, fat 5\%, carbohydrates $55 \%$, of 122 total kcal, reference \#U8959 version 63 Safe, Augy, France) and water were 123 provided ad libitum. Drd2-Cre mice (STOCK Tg(Drd2-cre) ER44Gsat/Mmucd, 124 Jackson laboratory) were used for in vivo fiber photometry $\mathrm{Ca}^{2+}$ imaging in the VTA.

\section{Behaviors}

127 Palatable binge eating-like paradigm. Intermittent daily access to the palatable 128 mixture (Intralipid 20\% w/v + sucrose 10\% w/v) was provided for 1 hour during 12-14 consecutive days at 10-11 AM in home cages. During time-locked binge sessions regular chow pellets were not removed. Volume $(\mathrm{mL})$ of consumed palatable mixture was measured at the end of the session.

132 Locomotor activity. Locomotor activity (LMA) was measured in an automated online 133 measurement system using an infrared beam-based activity monitoring system 134 (Phenomaster, TSE Systems GmbH, Bad Homburg, Germany).

135 Tail suspension. To record the activity GCaMP6f-expressing VTA neurons, mice 136 were suspended above the ground by their tails. $\mathrm{Ca}^{2+}$ imaging was performed before 137 and after tail suspension.

138 Exploratory drive in a new environment. To record the activity GCaMP6f-expressing 139 VTA neurons in a novelty-induced exploratory drive, mice were put in a new cage 140 (NC). $\mathrm{Ca}^{2+}$ imaging acquisition and analysis were performed before and after 141 changing the environment.

142 HFHS-induced increased VTA activity. Animals were provided with a high-fat high143 sugar pellet to validate the recording of VTA DA-neurons (activation) in Drd2-Cre 144 mice. $\mathrm{Ca}^{2+}$ imaging acquisition and analysis were performed before and after 145 feeding. 
146 Scruff restraint. Animals were immobilized by restraining to validate the recording of

147 VTA DA-neurons (inhibition) in Drd2-Cre mice. $\mathrm{Ca}^{2+}$ imaging acquisition and analysis

148 were performed before and after scruff restraint.

\section{Metabolic efficiency analysis}

Mice were monitored for whole energy expenditure (EE) or Heat $(\mathrm{H}), \mathrm{O}_{2}$ consumption and $\mathrm{CO}_{2}$ production, respiratory exchange rate $\left(\mathrm{RER}=\mathrm{VCO}_{2} / \mathrm{VO}_{2}\right.$, where $\mathrm{V}$ is a volume), and locomotor activity using calorimetric cages with bedding, food and water (Labmaster, TSE Systems GmbH, Bad Homburg, Germany). Ratio of gases was determined through an indirect open circuit calorimeter [for review (Arch et al., 2006; Even and Nadkarni, 2012)]. This system monitors $\mathrm{O}_{2}$ and $\mathrm{CO}_{2}$ concentration by volume at the inlet ports of a tide cage through which a known flow of air is being ventilated $(0.4 \mathrm{~L} / \mathrm{min})$ and compared regularly to a reference empty cage. For optimum analysis, the flow rate was adjusted according to the animal body weights to set the differential in the composition of the expired gases between 0.4 and $0.9 \%$ (Labmaster, TSE Systems GmbH, Bad Homburg, Germany). The flow was previously calibrated with $\mathrm{O}_{2}$ and $\mathrm{CO}_{2}$ mixture of known concentrations (Air Liquide, S.A. France). Oxygen consumption and carbon dioxide production were recorded every 15 min for each animal during the entire experiment. Whole energy expenditure (EE) was calculated using the Weir equation for respiratory gas exchange measurements. Food consumption was measured as the instrument combines a set of highly sensitive feeding sensors for automated online measurements. Mice had access to food and water ad libitum. To allow measurement of every ambulatory movement, each cage was embedded in a frame with an infrared light beam-based activity monitoring system with online measurement at $100 \mathrm{~Hz}$. The sensors for gases and detection of movements operated efficiently in both light and dark phases, allowing continuous recording.

173 Mice were monitored for body weight and composition at the entry and the exit of the experiment. Body mass composition (lean tissue mass, fat mass, free water and total water content) was analyzed using an Echo Medical systems' EchoMRI (Whole Body

176 Composition Analyzers, EchoMRI, Houston, USA), according to manufacturer's 177 instructions. Briefly, mice were weighed before they were put in a mouse holder and 178 inserted in the MRI analyzer. Readings of body composition were given within $1 \mathrm{~min}$. 
179 Data analysis was performed on Excel XP using extracted raw values of $\mathrm{VO}_{2}$

180 consumed, $\mathrm{VCO}_{2}$ production (expressed in $\mathrm{ml} / \mathrm{h}$ ), and energy expenditure $(\mathrm{kcal} / \mathrm{h})$.

181

182

Triglycerides, insulin and corticosterone measurements

183

Plasma circulating triglycerides (TG) were measured with a quantitative enzymatic measurement (Serum Triglyceride Determination Kit, Sigma-Aldrich, Saint-Louis, USA). Insulin dosage was performed with ELISA kit (mouse ultrasensitive insulin ELISA, ALPCO, Salem, NH, USA). Corticosterone was measured with RIA kit (MP Biomedicals, Orangeburg, NY, USA). All kits were used according to the manufacturer guidelines.

\section{Brown adipose tissue and telemetry body temperature measurements}

Infrared camera for BAT temperature: heat production was visualized using a highresolution infrared camera (FLIR E8; FLIR Systems, Portland, OR, USA). To measure brown adipose tissue (BAT) temperature, images of interscapular regions were captured before and after binge sessions. Infrared thermography images were analyzed using the FLIR TOOLS.

Telemetry body temperature: telemetric devices (Data Sciences International, accuracy $0.1^{\circ} \mathrm{C}$ ) were implanted according to the manufacturer instructions. Briefly, single-housed mice were anesthetized with isoflurane (1-2\%) and received ip injection of $10 \mathrm{mg} / \mathrm{kg}$ buprenorphine (Buprecare ${ }^{\circledR} 0.3 \mathrm{mg} / \mathrm{ml}$ ) and $10 \mathrm{mg} / \mathrm{kg}$ ketoprofen (Ketofen® 10\%). The transmitter (HD-XG; Data Sciences International) was placed intraperitoneally to measure longitudinal fluctuations of the core temperature. After surgery, animals were allowed to recover at $35^{\circ} \mathrm{C}$ and received a daily ip injection of ketoprofen (Ketofen® 10\%) for 3 consecutive days. During a 7day recovery period, mice were carefully monitored for body weight and behavior and had facilitated access to food. Implanted animals were then installed on their own receiver. Data were collected using the Ponemah $\AA$ software (DSI). The detection of the transmitter signals was accomplished by a radio receiver (body temperature and locomotor activity) and processed by a microcomputer system.

\section{Oral glucose tolerance test (OGTT)}

211 Oral glucose tolerance test was performed following the establishment of binge-like

212 behavior. Animals were fasted 6 hours before oral gavage of glucose $(2 \mathrm{~g} / \mathrm{kg})$. Blood 
213 glucose was directly measured from the vein blood tail using a glucometer (Menarini,

214 Diagnotics, Rungis, France) at 0, 15, 30, 45, 60, 90, and $120 \mathrm{~min}$. Blood samples

215 were taken at 0,15 and 30 and 60 min to measure insulin levels. Insulin dosage was

216 performed with ELISA kit (mouse ultrasensitive insulin ELISA (ALPCO, Salem, NH,

217 USA), according to the manufacturer guidelines).

218

219 Tissue preparation and immunofluorescence

220 For immunohistochemistry, animals were injected with i.p. pentobarbital (500 mg/kg,

221 i.p., Sanofi-Aventis, France). Once anaesthetized, animals were transcardially

222 perfused with $4^{\circ} \mathrm{C}$ PFA $4 \%$ for 5 minutes. Brains were collected, put overnight in PFA

$2234 \%$ and then stored in PBS, $4^{\circ} \mathrm{C}$. $30 \mu \mathrm{m}$-thick sections were sliced with a vibratome

224 (Leica VT1000S, France), and stored in PBS $4^{\circ} \mathrm{C}$. Sections were processed as

225 follows: Day 1: free-floating sections were rinsed in Tris-buffered saline (TBS; $0.25 \mathrm{M}$

226 Tris and $0.5 \mathrm{M} \mathrm{NaCl}, \mathrm{pH} 7.5$ ), incubated for 5 min in TBS containing $3 \% \mathrm{H} 2 \mathrm{O} 2$ and

$22710 \%$ methanol, and then rinsed three times for $10 \mathrm{~min}$ each in TBS. After $15 \mathrm{~min}$

228 incubation in $0.2 \%$ Triton $\mathrm{X}-100$ in TBS, sections were rinsed three times in TBS

229 again. Slices were then incubated overnight or $48 \mathrm{hrs}$ at $4^{\circ} \mathrm{C}$ with the following

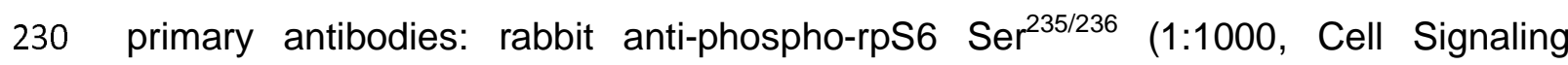

231 Technology, \#2211), rabbit anti-phospho-rpS6 $\operatorname{Ser}^{240 / 244}$ (1:1000, Cell Signaling

232 Technology, \#2215), rabbit anti-cFos (1:1000, Synaptic Systems, \#226 003) or

233 mouse anti-TH (1:1000, Millipore, \#MAB318). Sections were rinsed three times for 10

$234 \mathrm{~min}$ in TBS and incubated for $60 \mathrm{~min}$ with second anti-rabbit Cy3 AffiniPure (1:1000,

235 Jackson Immunoresearch). Sections were rinsed for $10 \mathrm{~min}$ twice in TBS and once in

236 TB (0.25 M Tris) before mounting.

237 Acquisitions were performed with a confocal microscope (Zeiss LSM 510). Images

238 used for quantification were all single confocal sections. The objectives and the

239 pinhole setting remained unchanged during the acquisition of a series for all images.

240 Quantification of immunoreactive cells was performed using the cell counter plugin of

241 the ImageJ software taking as standard reference a fixed threshold of fluorescence.

242

243 Western blotting

244 At the end of the binge session, the mouse head was cut and immediately immersed

245 in liquid nitrogen for 3 seconds. The brain was then removed and dissected on ice-

246 cold surface, sonicated in $200 \mu \mathrm{l}$ (dorsal striatum) and $100 \mu \mathrm{l}$ (nucleus accumbens) of 
$2471 \%$ SDS supplemented with $0.2 \%$ phosphatase inhibitors and $1 \%$ protease inhibitors,

248 and boiled for 10 minutes. Aliquots $(2.5 \mu \mathrm{l})$ of the homogenates were used for protein

249 quantification using a BCA kit (BC Assay Protein Quantitation Kit, Interchim Uptima,

250 Montluçon, France). Equal amounts of proteins $(10 \mu \mathrm{g})$ supplemented with a Laemmli

251 buffer were loaded onto 10\% polyacrylamide gels. Proteins were separated by SDS-

252 PAGE and transferred to PVDF membranes (Millipore). The membranes were

253 immunoblotted with the following antibodies: rabbit anti-phospho-Ser ${ }^{235 / 236}-$ rpS6

254 (1:1000, Cell Signaling Technology, \#2211), rabbit anti-phospho-Ser ${ }^{240 / 244}$-rpS6

255 (1:1000, Cell Signaling Technology, \#2215), rabbit anti-phospho-ERK (1:2000, Cell

256 Signaling Technology, \#4370), mouse anti-beta-actin (1:5000, Sigma Aldrich,

257 \#A1978). Detection was based on HRP-coupled secondary antibody binding using

258 ECL. The secondary antibodies were anti-mouse (1:5000, Dako, \#P0260) and anti-

259 rabbit (1:10000, Cell Signaling Technology, \#7074). Membranes were imaged using

260 the Amersham Images 680. Quantifications were performed using the ImageJ

261 software.

262

263

Drug treatments

264 The following compounds were used: insulin (0.5 U/kg, Novo Nordisk, Lot GT67422), 265 CCK-8S (10 ug/kg, Tocris, \#1166), liraglutide (100 ug/kg, gift from Novo Nordisk), 266 exendin 4 (10 ug/kg, Tocris, \#1933), leptin (0.25 mg/kg, Tocris, \#2985), AM251 (3 $267 \mathrm{mg} / \mathrm{kg}$, Tocris, \#1117), AM6545 (10 mg/kg, Tocris, \#5443), SKF81297 (5 mg/kg, 268 Tocris, \#1447), haloperidol (0.25 and $0.5 \mathrm{mg} / \mathrm{kg}$, Tocris, \#0931), SCH23390 (0.1 $269 \mathrm{mg} / \mathrm{kg}$, Tocris, \#0925), GBR12909 (10 mg/kg, Sigma Aldrich, \#D052), d270 amphetamine sulphate (2 mg/kg, Tocris, \#2813), JZL184 (8 mg/kg, Tocris, \#3836).

\section{Subdiaphragmatic vagotomy}

273 Prior to surgery and during 3 post-surgery days, animals were provided with ad 274 libitum jelly food (DietGel Boost Clear $\mathrm{H}_{2} \mathrm{O}$ ) to avoid the presence of solid food in the gastrointestinal tract. Animals received Buprécare® (Buprenorphine $0.3 \mathrm{mg}$ ) diluted $1 / 100$ in $\mathrm{NaCl}$ 0.9\% and Ketofen® (Ketoprofen $100 \mathrm{mg}$ ) diluted 1/100 in $\mathrm{NaCl} 0.9 \%$ and were anaesthetized with $3.5 \%$ isoflurane for induction and $1.5 \%$ for maintenance during the surgery. Their body temperature was maintained at $37^{\circ} \mathrm{C}$. Briefly, using a binocular microscope, the right and left vagus nerve branches were carefully isolated 
281 animals. Mice spent at least 3 weeks of post-surgery recovery period before being

282 used for the experimental procedures.

283

\section{Quantification of plasma eCBs}

285 Blood was collected before and after the last binge session and immediately 286 centrifuged to isolate the plasma. Plasma $(50 \mu \mathrm{L})$ was added to vials containing 287 dichloromethane $(8 \mathrm{~mL})$, methanol $(\mathrm{MeOH}, 4 \mathrm{~mL})$ (containing $\mathrm{BHT})$, water 288 (containing EDTA) and the internal standards (deuterated $N$-acylethanolamines, 289 deuterated 2-AG). Following extraction, the lipid-containing fraction was purified by 290 solid phase extraction (SPE). The endocannabinoids and related NAEs were 291 recovered from the SPE column using hexane-isopropanol 7:3 (v/v) and transferred 292 to injection vials (Bottemanne et al., 2019). The samples $(1 \mu \mathrm{L})$ were analyzed using 293 an Acquity UPLC® class H coupled to a Xevo TQ-S mass spectrometer (both from 294 Waters). For the separation we used an Acquity UPLC® BEH C18 (2.1x50 mm; 1.7 $\left.295 \mu \mathrm{m}, 40^{\circ} \mathrm{C}\right)$ column and a gradient $(200 \mu \mathrm{L} / \mathrm{min})$ between $\mathrm{MeOH}-\mathrm{H}_{2} \mathrm{O}$-acetic acid 296 (75:24.9:0.1; v/v/v) and $\mathrm{MeOH}$-acetic acid (99.9:0.1; v/v). Ionization was obtained 297 using an ESI source operated in the positive mode. A quantification and a 298 qualification transition were optimized for each analyte and MassLynx® used for data 299 acquisition and processing. For each analyte, the ratio between the AUC of the lipid 300 and the AUC of the corresponding internal standard was used for data normalization. Calibration curves were obtained in the same conditions.

302

\section{Viral production}

pAAV.Syn.Flex.GCaMP6f.WPRE.SV40 (titer $\geq 1 \times 10^{13} \mathrm{vg} / \mathrm{ml}$, working dilution 1:5) was a gift from Douglas Kim (Addgene viral prep \#100833-AAV9; https://www.addgene.org/100833/; RRID:Addgene_100833).

\section{Stereotaxic procedure}

309 Mice were anaesthetized with isoflurane and received $10 \mathrm{mg} / \mathrm{kg}$ intraperitoneal 310 injection (i.p.) of Buprécare® (Buprenorphine $0.3 \mathrm{mg}$ ) diluted $1 / 100$ in $\mathrm{NaCl} 0.9 \%$ and $31110 \mathrm{mg} / \mathrm{kg}$ of Ketofen® (Ketoprofen $100 \mathrm{mg}$ ) diluted 1/100 in $\mathrm{NaCl}$ 0.9\%, and placed 312 on a stereotactic frame (Model 940, David Kopf Instruments, California). 313 pAAV.Syn.Flex.GCaMP6f.WPRE.SV40 (0.3 $\mu$ l) was injected unilaterally (for fiber 314 photometry) into the ventral tegmental area (VTA) $(\mathrm{L}=-0.5 ; \mathrm{AP}=-3.4 ; \mathrm{V}=-4.4, \mathrm{~mm})$ of 
315 Drd2-Cre mice at a rate of $0.05 \mu \mathrm{l} / \mathrm{min}$. The injection needle was carefully removed

316 after 5 minutes waiting at the injection site and 2 minutes waiting halfway to the top.

317 Optical fiber for calcium imaging into the VTA was implanted $100 \mu \mathrm{m}$ above the viral

318 injection site. Animals were tested 4 weeks after viral stereotaxic injections.

320 Fiber photometry and data analysis

321 A chronically implantable cannula (Doric Lenses, Québec, Canada) composed of a 322 bare optical fiber (400 $\mu \mathrm{m}$ core, 0.48 N.A.) and a fiber ferrule was implanted $100 \mu \mathrm{m}$ 323 above the location of the viral injection site in the ventral tegmental area (VTA: $324 \mathrm{~L}=+/-0.5 ; \mathrm{AP}=-3.4 ; \mathrm{V}=-4.4, \mathrm{~mm})$. The fiber was fixed onto the skull using dental 325 cement (Super-Bond C\&B, Sun Medical). Real-time fluorescence signals emitted 326 from the calcium indicator GCaMP6f expressed by D2R-containing VTA neurons 327 were recorded and analyzed as previously described (Lerner et al., 2015). 328 Fluorescence was collected in the VTA using a single optical fiber for both delivery of 329 excitation light streams and collection of emitted fluorescence.

330 The fiber photometry setup used 2 light-emitting LEDs: $405 \mathrm{~nm}$ LED sinusoidally 331 modulated at $330 \mathrm{~Hz}$ and a $465 \mathrm{~nm}$ LED sinusoidally modulated at $533 \mathrm{~Hz}$ (Doric 332 Lenses) merged in a FMC4 MiniCube (Doric Lenses) that combines the 2 333 wavelengths excitation light streams and separate them from the emission light. The 334 MiniCube was connected to a Fiberoptic rotary joint (Doric Lenses) connected to the 335 cannula. A RZ5P lock-in digital processor controlled by the Synapse software 336 (Tucker-Davis Technologies, TDT, USA), commanded the voltage signal sent to the 337 emitting LEDs via the LED driver (Doric Lenses). The light power before entering the 338 implanted cannula was measured with a power meter (PM100USB, Thorlabs) before 339 the beginning of each recording session. The irradiance was $\sim 9 \mathrm{~mW} / \mathrm{cm}^{2}$. GCaMP6f340 emitted fluorescence was collected by a femtowatt photoreceiver module (Doric 341 Lenses) through the same fiber patch cord. The signal was then received by the 342 RZ5P processor (TDT). On-line real-time demodulation of the fluorescence due to 343 the $405 \mathrm{~nm}$ and the $465 \mathrm{~nm}$ excitations was performed by the Synapse software

344 (TDT). A camera was synchronized with the recording using the Synapse software.

345 Signals were exported to Python 3.0 and analyzed off-line using TDT Python SDK 346 packages. 
347 For the new cage paradigm, signal analysis was performed on two-time intervals:

348 one extending from -60 to 0 seconds (home cage, $\mathrm{HC}$ ) and the other from 0 to 60

349 seconds (new cage, NC).

350 For the tail suspension paradigm, signal analysis was performed on two-time

351 intervals: one extending from -60 to 0 seconds (baseline) and the other from 0 to 120

352 seconds (tail suspension).

$353 \Delta \mathrm{F} / \mathrm{F}$ was calculated as [(465 nm signal test $_{-}$- fitted $405 \mathrm{~nm}$ signal $\left.{ }_{\text {ref }}\right) /$ fitted $405 \mathrm{~nm}$

354 signal ${ }_{\text {ref] }}$. To compare signal variations between the two conditions (NC vs HC or tail

355 suspension vs baseline) for each mouse a difference between $A U C s\left(A \cup C_{2}-A U C_{1}\right)$

356 was used.

357

358 Statistics

359 Data are presented as mean \pm SEM. All statistical tests were performed with Prism 6 360 (GraphPad Software, La Jolla, CA, USA). The detailed statistical analyses are listed 361 in the Supplementary Table 1. Depending on the experimental design, data were 362 analyzed using either Student t-test (paired or unpaired) with equal variances, One363 way ANOVA or Two-way ANOVA. In all cases, the significance threshold was 364 automatically set at $p<0.05$. ANOVA analyses were followed by Bonferroni post hoc 365 test for specific comparisons only when overall ANOVA revealed a significant 366 difference (at least $p<0.05$ ). 


\section{Results}

368

369

370

371

372

373

374

375

376

377

378

379

380

381

382

383

384

385

386

387

388

389

390

391

392

393

394

395

396

397

398

399

400

\section{Time-locked access to palatable diet induces adaptation of nutrient partitioning} and metabolic efficiency

Several preclinical paradigms of bingeing are widely used to model humans' eating disorders (Avena, 2010). However, the majority of currently available paradigms mainly rely on ( $i$ ) prior alterations of basal homeostasis (food or water restriction/deprivation, stress induction), (ii) dietary exposure to either high-sugar or high-fat foods or (iii) the absence of food choice during bingeing periods.

We therefore adapted existing protocols to better study reward and homeostatic components of food intake during binge eating (BE). In our protocol, since dietary mixtures of fat and sugar lead to enhanced food reward properties (DiFeliceantonio et al., 2018), a highly palatable milkshake (sugar and fat) was designed to promote intense craving and reward-driven feeding. Time-locked access to this milkshake was sufficient to drive escalating binge-like consumption with no need of restricting access to chow diet (Figure 1A). In that regard, we are confident that our BE model is preferentially driven by reward values over metabolic demands since animals are neither food nor water restricted.

Mice intermittently exposed to this dietary palatable mixture rapidly maximized their intake within a few days, reaching an averaged consumption of $1.4 \mathrm{~mL}$ in $1 \mathrm{~h}(\sim 3.4$ $\mathrm{kcal} / \mathrm{h}$ ) (Figure 1B). Importantly, intermittent (1h/day) exposure to palatable noncaloric sucralose or saccharin solutions did not lead to escalating binge-like consumption (Suppl. Figure 1A, B), indicating that calorie content, beyond taste perception itself, is necessary to drive incentive salience and BE-like behavior.

This palatable food consumption was simultaneously associated with an increased anticipatory locomotor activity $\sim 2$ hours before food access and lasted for another $\sim 1-2$ hours following access (Figure $1 \mathbf{C}, \mathbf{C}^{1}$ ), with no changes in the ambulatory activity during the dark phase (Figure 1C). The same animals were characterized by a significant reduction in spontaneous nocturnal food intake (Figure 1D, $\mathbf{D}^{1}$ ). However, in bingeing animals the overall calories intake [standard diet (SD) + palatable food (PF)] remained identical to controls, thus indicating a conserved isocaloric maintenance in calories consumption despite reward-driven food intake (Figure 1E). Importantly, isocaloric feeding was associated with conserved body weight (BW) and body composition during the experimental protocol (Figure 1F, 
401 Suppl. Figure 1C, D). Next, we investigated the consequence of palatable food 402 exposure and BE progression onto metabolic efficiency. Indirect calorimetry analysis 403 revealed an increase in the respiratory exchange ratio (RER) before and after 404 intermittent palatable food consumption (Figure 1G, $\mathbf{G}^{1}$ ), and a stark reduction was 405 detected in the dark phase (Figure 1G), thereby highlighting a metabolic shift of 406 energy substrates use (from carbohydrates to lipids as indicated by RER $\sim 1$ or RER $407 \sim 0.7$ respectively). Such metabolic shift toward lipid substrates was further confirmed 408 by the modulation of fatty acids oxidation (FAO, Suppl. Figure 1E). In addition, we 409 also observed an increase in energy expenditure (EE) during the food anticipatory 410 and consummatory phases (Figure $\mathbf{1 H}, \mathbf{H}^{\mathbf{1}}$ ). Furthermore, infrared thermography 411 analysis revealed that BE was associated with a transient increase in brown adipose 412 tissue (BAT) energy dissipation (Figure 1I) while telemetric recording of core body 413 temperature revealed a BE specific increase during the anticipatory, consummatory 414 and post-prandial phases (Figure 1J, J', Suppl. Figue 1F) and a sharp reduction 415 during the last hours of the dark phase in BE animals. Overall, changes in core body 416 temperature were fostered around the time of time-locked palatable food access and 417 overlapped with the increase in locomotor activity (Figure 1J, K).

418 Access to calories-rich food and time-restricted feeding are invariably associated with 419 changes in circulating signals reflecting metabolic and behavioral adaptations 420 (Oosterman et al., 2020). In line with this, we observed that our model of BE was associated with reduced circulating triglycerides (TG) and insulin and concomitant increase in circulating corticosterone during the anticipatory phase (Figure 2A-C) while overall insulin sensitivity, as assessed by oral glucose tolerance test, remained unchanged (Figure 2D, E). These data support the notion that homeostatic adaptations occurring during time-locked palatable feeding lead to changes in lipidsubstrates utilization and promotes adaptive activation of the hypothalamic-pituitaryadrenal (HPA) axis.

428 Overall, these results point to a rapid allostatic adaptation of metabolic and 429 behavioral readouts, during which animals optimize their palatable food consumption 430 and physiologically adapt by compensating the time-locked calories load to maintain 431 a stable body weight.

432 
434 Dopamine (DA) neurons and DA-sensitive structures, such as the dorsal striatum

435 (DS) and the nucleus accumbens (NAc), are critical players in reward-based 436 paradigms but also in BE disorders (Balodis et al., 2015; Palmiter, 2007; Spierling et 437 al., 2020; Wang et al., 2011). Here, we investigated whether bingeing modulated the 438 DA-associated signaling machinery. Thus, we used the activation (phosphorylation) 439 of the ribosomal protein S6 (rpS6) and the extracellular signal-regulated kinases 440 (ERK) as functional readouts of DA-dependent molecular activity (Gangarossa et al., 441 2013a, 2013b, 2019; Valjent et al., 2019). We first investigated such molecular 442 activations in bingeing mice before and after reward-diet consumption (Figure $3 \mathbf{A}$ ) in 443 the DS and NAc (Figure 3B).

444 The food anticipatory phase was associated with an increase in ERK activation only 445 in the DS (Figure 3C, D), mostly reflecting the increased locomotor activity during the 446 anticipatory phase. Importantly, palatable food consumption induced an increase in 447 phospho-ERK and phospho-rpS6 (at both $\mathrm{Ser}^{235 / 236}$ and $\mathrm{Ser}^{240 / 244}$ sites) in both DS 448 and NAc (Figure 3C-E). Interestingly, acute (single) consumption of palatable diet 449 failed in triggering ERK and rpS6 activation (Figure $3 \mathbf{C}-\mathbf{E}$ ), thus revealing that 450 molecular adaptation of the DA signaling in the DS/NAc are tightly dependent on the 451 full establishment of the binge behavior and not only on the consumption of the 452 palatable food. Immunofluorescence analysis revealed that BE-induced rpS6 453 activation was clearly evident in the DS and NAc (Figure 3F, G).

$454 \quad$ Next, we wondered whether food-reward anticipatory and/or consummatory 455 phases were followed by adaptive changes in DA-evoked behavioral responses. 456 Thus, we treated mice with GBR12909 (10 mg/kg), a specific dopamine transporter 457 (DAT) blocker that prevents the presynaptic reuptake of DA, ultimately leading to its 458 accumulation into the synaptic cleft. Interestingly, we observed a different behavior 459 depending on BE phases (anticipatory vs consummatory). Before palatable food 460 access, GBR treatment increased locomotor activity in both bingeing and control 461 animals (Figure 4A, $\mathbf{A}^{\mathbf{1}}$ ). However, when GBR was administered following palatable 462 food consumption (1h), GBR-induced locomotor response was blunted in bingeing 463 animals (Figure 4B, $\mathbf{B}^{1}$ ). These results indicate that BE-induced physiological 464 adaptations are characterized by the enabled ability for palatable food to impinge on 465 DA release and action. At the postsynaptic level, DA acts onto medium spiny 466 neurons (MSNs) which express either the dopamine D1R (D1R-MSNs) or D2R (D2R$467 \mathrm{MSNs}$ ). In order to discriminate the role of D1R vs D2R signaling in BE, we 
468 pretreated animals with the D1R antagonist SCH23390 $(0.1 \mathrm{mg} / \mathrm{kg})$ or vehicle (Veh) 469 before providing access to palatable diet. SCH23390 dramatically reduced palatable 470 food consumption (Figure 4C). On the contrary, pretreatment with haloperidol (0.25 471 and $0.5 \mathrm{mg} / \mathrm{kg}$ ) did not dampen palatable food consumption (Figure 4D), even at 472 doses $(0.5 \mathrm{mg} / \mathrm{kg}$ ) known to trigger cataleptic responses (Kobayashi et al., 1997; 473 Radl et al., 2018). This evidence suggests that loss of control on palatable bingeing 474 primarily relies on D1R signaling. In line with this event, activation of striatal D1R 475 leads to downstream phosphorylation of rpS6 and ERK (Biever et al., 2015; 476 Gangarossa et al., 2013a). Importantly, the adaptive molecular changes in the DS 477 and NAc also required D1R activation since SCH23990 (0.1 mg/kg) largely 478 suppressed BE-associated phosphorylations of rpS6 in both DS (Figure 4E) and 479 NAc (Figure 4F). These results indicate that D1R is critical in driving palatable food 480 consumption and its associated molecular activations in the specific context of BE. Of 481 note, although SCH23390 reduced anticipatory locomotor activity in pretreated 482 animals, basal locomotor activity in naive animals was not impaired (Figure $\mathbf{4 G}, \mathbf{G}^{\mathbf{1}}$ ), 483 thereby excluding the confounding effects due to changes in basal locomotor activity. 484 Furthermore, a compensatory rescue in chow intake was observed in SCH23390485 pretreated bingeing animals during the dark phase, excluding potential long-lasting 486 effects of the D1R inhibition (Figure $\mathbf{4 H}$ ). To further validate the hypothesis that D1R 487 may be involved in BE-elicited dopamine modifications, we measured the locomotor 488 activity triggered by the activation of D1R with its direct agonist SKF81297 (5 mg/kg) 489 at the end of the BE session (1h after food access). At the end of the session, the 490 D1R agonist SKF81297 (5 mg/kg) was administered to control and bingeing animals. 491 Interestingly, we observed an earlier (first $30 \mathrm{~min}$ ) significant increase in locomotor 492 activity in bingeing animals compared to control mice (Figure $4 \mathbf{I}, \mathbf{I}^{\mathbf{1}}$ ), although no 493 major differences were detected during the cumulative 2-hrs response (Figure $\mathbf{4} \mathbf{I}^{\mathbf{1}}$ ).

494 Overall, our results reveal that the critical phases surrounding palatable food 495 consumption in the context of BE profoundly affect DA-associated signaling and 496 promote consummatory and behavioral responses that primarily rely on D1R497 dependent signaling.

498

\section{Peripheral endocannabinoids govern binge eating}

500 Recent studies have highlighted the role of enteric neuronal and endocrine systems 501 in the regulation of food reward-seeking and DA-associated behaviors (de Araujo et 
502 al., 2020; Reichelt et al., 2015). We therefore tested whether gut-born metabolic

503 signals had a privileged action onto BE-like consumption of palatable diet when

504 compared to other known circulating satiety signals.

$505 \quad$ Firstly, we observed that peripherally injected leptin $(0.25 \mathrm{mg} / \mathrm{kg})$, or insulin

$506(0.5 \mathrm{U} / \mathrm{kg})$, did not trigger any reduction in palatable food consumption when injected

507 in bingeing animals (Figure 5A). Then, we investigated whether gut-born satiety

508 signals retained anorectic properties with a similar protocol. Glucagon-like peptide

509 hormone (GLP-1) is a satiety signal produced by the endocrine cells of the intestine.

510 GLP-1R agonists, exendin-4 and liraglutide, are known to decrease food intake

511 (Ladenheim, 2015). Both GLP-1 mimetic drugs (exendin-4, $10 \mu \mathrm{g} / \mathrm{kg}$ and liraglutide,

$512100 \mu \mathrm{g} / \mathrm{kg}$ ) successfully reduced binge-consumption of palatable diet (Figure 5A).

513 Similarly, the cholecystokinin (CCK) analog CCK-8S $(10 \mu \mathrm{g} / \mathrm{kg})$ acutely decreased

514 palatable food intake (Figure 5A).

515 These results indicate that dietary-induced BE is associated with the resistance to

516 the satiety action of leptin and insulin, while the anorectic action of gut-born signals

517 remains unaltered.

518 Bioactive lipids, among which endocannabinoids (eCBs), are important signals to

519 relay nutrients-induced adaptive responses in the gut-brain axis (DiPatrizio and

520 Piomelli, 2015; Lau et al., 2017). Therefore, we explored the plasticity and functions

521 of eCBs signaling in dietary-induced BE.

522 First, we pharmacologically inhibited the CB1R with the selective inverse agonist

523 AM251 (3 mg/kg). Blockade of CB1R dramatically reduced BE-like consumption

524 (Figure 5A). Next, we wondered whether bingeing was accompanied by alterations

525 in circulating peripheral eCBs [anandamide (AEA) and 2-arachidonoylglycerol (2-

$526 \mathrm{AG}$ )] and eCBs-related species [docosahexanoyl ethanolamide (DHEA),

527 oleoylethanolamide (OEA)]. While circulating $N$-acylethanolamines (AEA, DHEA,

528 OEA) remained unaffected, time-locked palatable feeding induced a significant

529 increase in 2-AG immediately after food consumption (Figure 5B).

$530 \quad$ Since the CB1R is highly expressed in both peripheral and central nervous

531 systems, we were eager to distinguish the respective contribution of central or

532 peripheral of CB1R signaling in BE outputs. Thus, we used the peripherally restricted

533 CB1R neutral antagonist AM6545 (10 mg/kg, i.p.), a compound unable to cross the

534 blood brain barrier (Boon et al., 2014; Cluny et al., 2010; Tam et al., 2010).

535 Pretreatment with AM6545 (10 mg/kg, $1 \mathrm{~h}$ before palatable-food access) induced a 
536 stark abolishment of BE consumption when administered acutely (Figure 5C).

537 Conversely, the increase of circulating eCB achieved through the pharmacological

538 inhibition (JZL184, $8 \mathrm{mg} / \mathrm{kg}$ ) of the enzyme responsible of 2-AG hydrolysis, the

539 monoacylglycerol lipase (MAGL) (Long et al., 2009), resulted in an increase of

540 palatable food consumption that was fully prevented by AM6545 (Figure 5C). This

541 bidirectional modulatory action of eCBs/CB1R onto BE did not show signs of

542 desensitization and remained efficient throughout 4 days of daily pharmacological

543 intervention (Figure 5D). In the same line, thermogenic and locomotor activity

544 analyses revealed that pretreatment with AM6545 strongly dampened both the

545 anticipatory and consummatory phases of BE (Figure 5E, F).

546 These results indicate that peripheral CB1R signaling is sufficient to control

547 compulsive eating in BE.

548

549

We next explored how peripheral CB1R signaling modulates metabolic 550 efficiency in the context of BE. Pretreatment with $A M 6545$ (10 mg/kg, i.p.) 551 significantly increased fatty acid oxidation (FAO) (Figure $\mathbf{5 G}, \mathbf{G}^{\mathbf{1}}$ ). Importantly, this

552 AM6545-induced increased FAO did not depend neither on reduced calorie intake

553 (Binge session) or basal calorie contents (NoBinge session) (Figure $\mathbf{5 G}^{2}$ ) nor on 554 altered energy expenditure (EE) (Suppl. Figure 2A).

555 These results indicate that acute manipulation of peripheral, brain-excluded, eCB

556 tone affects nutrient partitioning and promotes a shift towards whole body lipid-

557 substrate utilization.

558 Importantly, we observed neither blunted palatable feeding responses (Figure $5 \mathbf{H}$ ) 559 nor increased FAO (Figure 5I) when AM6545 was orally (p.o.) administered. These 560 results suggest that, in our behavioral model, CB1R-mediated homeostatic 561 adaptations do not depend on the lumen-oriented apical CB1R expression in 562 endothelial or enteroendocrine intestinal cells (Argueta et al., 2019; Sykaras et al., 563 2012) but rather on non-lumen-oriented CB1R. Recent reports have indicated that $564 \mathrm{CB1R}$ is also expressed in vagal afferent neurons (Burdyga et al., 2010; Egerod et 565 al., 2018). To discriminate between all vagal afferents, we performed a meta-analysis 566 on recent single-cell transcriptomic results (Bai et al., 2019) obtained through a path567 specific viral strategy of gut segments (Figure 5J). This analysis revealed, that Cnr1 568 (gene encoding for CB1R), but not Cnr2, was highly enriched in all segments of the 569 gut-brain vagal axis (Figure 5K, Suppl. Figure 2B, C) and that, together with well- 
570 known afferent markers (Slc17a6, Scn10a, Htr3a, Cartpt, Grin1, Phox2b), Cnr1 may

571 be considered as a constitutive marker of vagal sensory neurons.

572

573 The gut-brain vagal axis is required for eCBs-mediated effects

574 We have shown that gut-brain satiety signals and peripheral CB1R signaling retained

575 full anorectic potency while circulating signals, leptin and insulin, failed to decrease

576 feeding in our BE model (Figure 5). Given that peripheral eCBs can mediate their

577 action in part through the vagus nerve (Bellocchio et al., 2013) this result strongly

578 supports a critical implication for gut-born nervous inputs in the

579 establishment/maintenance of BE-like behavior. Thus, we took advantage of

580 subdiaphragmatic gut vagotomy (VGX) to investigate whether the eCBs-vagus axis

581 was necessary/sufficient to mediate the anti-bingeing effects. In sham mice, injection

582 of the peripherally restricted CB1R antagonist AM6545 led to a strong increase in

583 cFos-expressing neurons in the nucleus tractus solitarius (NTS) and the area

584 postrema (AP) while the signal was fully abolished in vagotomized mice (Figure 6A,

$585 \mathbf{A}^{1}, \mathbf{A}^{2}$ ). In addition, we observed a vagus-dependent increase in cFos also in the

586 NTS-projecting lateral parabrachial nucleus (IPBN) (Figure 6A), indicating that

587 peripheral modulation of eCB action influences central brain pathways.

588 We also observed that the integrity of the vagus nerve was essential to mediate the 589 anorectic action of AM6545 on BE behavior (Figure 6B). Importantly, although

590 vagotomy (VGX) per se was associated with a decrease in time-locked hedonic 591 feeding and consequent BE-derived compensatory homeostatic adaptations (Suppl.

592 Figure 3), peripheral CB1R antagonist did not trigger an additive anorectic response

593 (Figure 6B) in VGX mice compared to sham mice. Furthermore, vagotomy abolished

594 the increase in FAO following AM6545 administration observed in sham mice (Figure

595 6C, $\mathbf{C}^{\mathbf{1}}, \mathbf{6 D}, \mathbf{D}^{\mathbf{1}}$ ). These results demonstrate that the gut-brain vagal communication

596 routes feeding and the metabolic components associated with BE.

597 These vagus-dependent homeostatic adaptations promoted by peripheral blockade

598 of CB1R prompted us to investigate whether AM6545 was able to alter the activity of

599 brainstem-projecting central structures that control feeding. Indeed, AM6545 induced

600 a strong vagus-dependent increase of cFos-neurons in the hypothalamic regions

601 PVN and DMH (Figure 6E, $\mathbf{E}^{1}, \mathbf{F}, \mathbf{F}^{\mathbf{1}}$ ), thereby indicating that the metabolic

602 adaptations induced by peripheral blockade of CB1R require a vagus-mediated

603 NTS $\rightarrow$ PBN $\rightarrow$ hypothalamus circuit whose nodes' activation control feeding and 
604 energy homeostasis (Cheng et al., 2020; D’Agostino et al., 2016; Grill and Hayes, 605 2012).

606

607 Peripheral CB1R signaling routed by the vagus nerve controls the activity of 608 VTA dopamine neurons

609 Since palatable bingeing also strongly relies on central DA-dependent mechanisms

610 (Figure 3, 4), we therefore explored the functional connection between peripheral

611 eCBs and gut-to-brain vagal axis in the modulation of the reward DA system. Naive

612 mice were pretreated with $\operatorname{AM6545~(10~mg/kg,~i.p.)~or~vehicle~before~being~}$

613 administered with the DAT blocker GBR12909 (10 mg/kg). Blockade of peripheral

614 CB1R drastically reduced GBR-induced locomotor activity (Figure 7A, $\mathbf{A}^{\mathbf{1}}$ ) as well as

615 GBR-triggered cFos induction in the striatum (Figure 7B, B ${ }^{1}$ ). Interestingly, AM6545

616 failed in contrasting amphetamine-induced locomotor activity (Figure 7C), thereby

617 suggesting that inhibition of peripheral CB1R may modulate the intrinsic activity of

618 DA-neurons rather than altering evoked DA release events.

619 These results reveal that inhibition of peripheral CB1R, besides promoting satiety 620 and FAO, may dampen reward-driven feeding also by concomitantly reducing DA621 neurons activity and consequent activation of the dopaminoceptive structures.

622 To directly address this point, VGX mice were pretreated with AM6545 prior to 623 receiving GBR12909. Remarkably, ablation of the vagus nerve prevented AM6545624 induced blunting of GBR-elicited locomotor activity (Figure 7D, $\mathbf{D}^{\mathbf{1}}$ ). Moreover, this 625 vagus-to-brain effect was further highlighted by the lack of action of AM6545 when 626 orally administered (Figure $7 E, E^{1}$ ), as reported for palatable bingeing (Figure $6275 \mathrm{H}$ ). When AM6545 was primarily contained to the lumen and epithelial surface of 628 the gut through oral administration, no effects on GBR-mediated hyperlocomotion 629 were observed.

630 This result supports the notion that the modulatory action of peripheral eCB signaling 631 onto the gut-brain axis in controlling reward BE is located outside of gut lumen.

632 Finally, to fully establish that peripheral inhibition of CB1R modulates the activity of 633 dopamine VTA neurons, we performed cell type-specific in vivo $\mathrm{Ca}^{2+}$ imaging of DA634 neurons in presence or absence of AM6545. We took advantage of the Drd2-Cre 635 mouse line to express virally mediated GCaMP6f in VTA DA-neurons (Figure 7F) 636 since they co-express the autoreceptor D2R (Anzalone et al., 2012; Usiello et al., 637 2000). Indeed, using this mouse line we were able to detect activation and inhibition 
638 of VTA DA-neurons following rewarding (high-fat high-sugar pellet) or aversive (scruff 639 restraint) events (Suppl. Figure 4A, B), respectively. To trigger the activity of DA-

640 neurons independently from food- or drugs-associated stimuli, we used two 641 paradigms that modulate DA-neurons activity: exposure to a new environment 642 (Takeuchi et al., 2016) which promotes exploration and tail suspension (Kolata et al., 643 2018) (Figure 7G). Importantly, inhibition of peripheral CB1R (AM6545) led to a 644 reduced activation of VTA DA-neurons in both paradigms (Figure $7 \mathbf{H}$, I), thus 645 revealing that peripheral $C B 1 R$ lead to the abolishment of $B E$ through the activation 646 of satietogenic (Figure 5, 6) and the inhibition of reward circuits (Figure 7). 


\section{Discussion}

648

649 A characteristic feature of feeding behavior is its key ability to dynamically adapt to 650 sensory and environmental stimuli signaling food availability. Such adaptive strategy 651 is even more pronounced when food is palatable and energy-dense. Indeed, the 652 control of feeding strategies requires complex and highly interacting systems that can 653 hardly be unequivocally attributed to single structures or circuits.

654 In our study, by using in vivo integrative approaches, we observed that, first, 655 palatable time-locked feeding mobilizes both homeostatic and hedonic components 656 of feeding through fast, but yet physiological, allostatic adaptations. Second, such 657 allostatic adaptations require a concerted involvement of central DA (hedonic drive) 658 and peripheral eCBs signaling (homeostatic and hedonic drive). Third, the permissive 659 role of peripheral eCBs fully relies on the vagus nerve which, by a polysynaptic 660 circuit, controls the activity of both satietogenic and reward (dopamine) structures. 661 Fourth, our results point to peripheral CB1R neutral antagonists as promising 662 therapeutic tools to counteract eating as well as reward-related disorders.

663 Overall, our study describes for the first time the fundamental role of eCB/vagal gut664 brain transmission as a core component of binge eating and its behavioral, cellular 665 and molecular adaptations.

666

667

Here, by investigating the pathways involved in hedonic feeding in absence of 668 induced hunger or energy deprivation, we provide evidence that the hedonic drive to eat, as triggered by our intermittent time-locked model, promotes rapid homeostatic compensations leading to escalating consumption of palatable food and to allostatic adaptations of energy metabolism. As such, caloric demands are fulfilled and classical energy-mediated homeostatic signals (leptin, insulin) do not seem to spontaneously interfere, thus providing us the opportunity to study food intake-related integrative pathways with the abstraction of the homeostatic vs hedonic discrepancy.

675 In line with clinical data (Carr and Grilo, 2020; Hutson et al., 2018), we observed that 676 binge-like feeding in lean animals is not necessarily associated with overweight gain 677 and does not lead to disrupted body weight homeostasis. On the contrary, through an 678 allostatic feed-forward mechanism, mice rapidly adapt to palatable food availability by 679 reducing their nocturnal feeding patterns in order to maximize time-locked (1h) 680 hedonic feeding. Such adaptations, ranging from increased anticipatory feeding 
681 phase to pre-feeding increased corticosterone levels and food intake maximization,

682 all represent key hallmarks of the compulsive and emotional states of BE patients

683 (Bake et al., 2014; Muñoz-Escobar et al., 2019; Naish et al., 2019). The anticipatory

684 feeding phase was associated with decreased levels of plasma TG and insulin, 685 whereas both anticipatory and consummatory phases were characterized by 686 increased energy expenditure, core temperature and metabolic efficiency, thereby 687 suggesting a metabolic shift of nutrients' use. This observation perfectly mirrors the 688 allostatic theory, which stands on the fact that an organism anticipates and adapts to 689 environmental changes while accordingly adjusting several physiological parameters 690 to maintain stable physiological states (De Ridder et al., 2016; Ramsay and Woods, 691 2014). Allostatic mechanisms have classically been discussed in terms of stress692 related regulatory events. However, the hedonic value of a stimulus (food, 693 recreational drugs) can function as a feed-forward allostatic factor (George et al., 694 2012).

695

696

During time-locked palatable feeding, such allostatic adaptations (anticipation and consumption of palatable food) required intact DA signaling. In fact, analysis of key DA-activated downstream phospho-targets in the DS and NAc highlighted specific patterns of molecular activation. Notably, while the anticipatory phase was associated with an increase in ERK and $\mathrm{rpS6}^{\mathrm{Ser} 235 / 236}$ phosphorylations, the consummatory phase was also accompanied by a robust increase in mTORmediated rpS6 ${ }^{\text {Ser240/244 }}$ activation. Such signaling events, which did not depend on a single episode of palatable food intake, required the dopamine D1R as administration of $\mathrm{SCH} 23390$, but not of the D2R antagonist haloperidol, prevented binge-like behavior and its associated molecular modifications. This is of interest since, contrary to the well-known molecular insights of drugs of abuse which require the D1R (Bertran-Gonzalez et al., 2008; Gore and Zweifel, 2013; Kai et al., 2015; Luo et al.,

708 2011; Sutton and Caron, 2015), food-related disorders have usually been predominantly associated with altered D2R signaling (Caravaggio et al., 2015; Kenny et al., 2013; Michaelides et al., 2012). These results reveal that binge eating, characterized by transients and sudden urges of hedonic drive, requires, at least in

712 its early phases, a D1R-mediated transmission. This D1R-dependent mechanism is 713 in line with the affinity and time-dependent dynamics of dopamine effects (Luo et al., 714 2011) as well as with the molecular action of released DA which, by binding to 
$715 \mathrm{Ga}(\mathrm{olf})$-coupled D1R, would trigger the activation of the aforementioned pathways,

716 whether activation of the Gi-coupled D2R would lead to their inhibition (Beaulieu and

717 Gainetdinov, 2011; Valjent et al., 2019). However, in clear opposition to

718 psychostimulants, which directly act at central DA synapses, food and food-mediated

719 behaviors impact DA transmission through a plethora of indirect and often

720 peripherally born long-range acting mediators. In fact, the central regulation of

721 feeding behavior, either in its homeostatic and/or hedonic components, tightly

722 depends on the fine orchestration of peripheral humoral and neuronal signals.

723 Notably, nutrients, as demonstrated by intragastric infusion of fat and sugar (Alhadeff

724 et al., 2019; Han et al., 2016; Hankir et al., 2017; Tellez et al., 2016), or gut-born

725 signals (Cone et al., 2014; Fulton et al., 2006; Jerlhag et al., 2007; Reddy et al.,

726 2018), are sufficient to modulate DA release in reward-related structures. Here, we

727 observed that gut-born signals such as CCK, GLP1 and endocannabinoids (eCBs)

728 are essential in gating bingeing. In particular, we found that time-locked consumption

729 of palatable food was associated with a rise in peripheral endogenous eCBs, notably

730 2-AG. Furthermore, inhibition of the 2-AG-degrading enzyme MAG lipase resulted in

731 a potentiation of palatable food consumption. Thus, by taking advantage of a

732 peripherally restricted CB1R antagonist (Tam et al., 2010), we observed that

733 administration of AM6545 was able to fully abolish both anticipatory and

734 consummatory phases of hedonic feeding as well as the potentiated feeding induced

735 by the MAG lipase inhibitor. These effects agree with the literature showing that

736 endogenous peripheral eCBs are highly and dynamically modulated in eating

737 disorders, and act as powerful mediators of the gut-to-brain integration (Gómez et al.,

738 2002).

739

Previous studies have shown that chronic administration of AM6545 promoted

741 long-term maintenance of weight loss and reduction of dyslipidemia in obesity (Boon

742 et al., 2014; Cluny et al., 2010; Tam et al., 2010). Here, we show that single, as well

743 as repeated (4 days), administration of AM6545 potently inhibits binge eating without

744 altering body weight. The anorectic effects of peripheral blockade of CB1R have

745 been, at least in part, attributed to the property of CB1R antagonists to promote fatty

746 acid oxidation (FAO). In agreement with these studies, we have observed that acute

747 administration of AM6545 was able to dramatically increase FAO independently of

748 food intake. However, here we also demonstrate that such effects require the vagus 
749 nerve since subdiaphragmatic vagotomy prevents both AM6545-mediated bingeing

750 blockade and FAO increase. The action of endogenous eCBs as well as of AM6545

751 on CB1R-expressing vagal afferents (Burdyga et al., 2010; Egerod et al., 2018) may

752 explain our results. In fact, an increase in endogenous eCBs during palatable

753 feeding, in virtue of the inhibitory Gi-coupled signaling of CB1R, would inhibit the 754 vagus nerve thus delaying NTS-reaching satiety signals and promoting food intake.

755 On the contrary, peripheral blockade of CB1R, especially when peripheral eCB levels

756 are endogenously high (i.e. binge eating, bulimia, obesity), would lead to a prompt

757 disinhibition and to the concomitant activation of satietogenic brain pathways

758 (NTS $\rightarrow$ PBN $\rightarrow$ PVN). Interestingly, it is worth to mention that in a non-hedonic feeding

759 paradigm the anorectic properties of AM6545 did not require the vagus nerve (Cluny

760 et al., 2010) and that under fasting or lipoprivic conditions the systemic CB1R inverse

761 agonist SR141716A (rimonabant) modulated feeding by the sympathetic nervous

762 system (SNS) (Bellocchio et al., 2013). Another site of action for peripheral eCBs is

763 represented by CB1R-expressing gut cells (Argueta et al., 2019; Godlewski et al.,

764 2019). Interestingly, oral administration of a peripheral CB1R antagonist resulted in a

765 reduction of alcohol intake via a ghrelin-dependent and vagus-mediated mechanism

766 (Godlewski et al., 2019). However, in our reward-driven feeding model, oral

767 administration of AM6545 failed in mediating its modifications on metabolic efficiency

768 as well as in preventing bingeing behavior, thus suggesting that lumen-oriented

769 apical CB1R may not be involved in our mechanism. Intriguingly, recent studies have

770 uncovered that sensory neuropod cells in the gut (Bohórquez et al., 2014, 2015) can

771 synaptically signal with the juxtaposed vagal afferents using, among other possible

772 mediators (Glass et al., 2017; Haber et al., 2017), the fast-acting neurotransmitter

773 glutamate (Kaelberer et al., 2018). Whether this specialized gut-to-nerve synapse

774 also mobilizes eCBs, as it occurs at most central excitatory synapses, remains to be

775 determined.

776 Overall, it would not be hazardous to suggest that peripheral eCBs may impact

777 feeding patterns through different integrative mechanisms which, depending on the

778 location of peripheral CB1R, may strongly modulate distinct functional outputs.

779 Indeed, these results call for a need to use cell-type and tissue-type-specific

780 strategies to selectively delete CB1R and/or eCBs-producing enzymes in distinct

781 compartments of the gastrointestinal tract and in the neuronal gut-brain axis. 
782 In order to anatomically provide an explanatory gut-to-brain circuit able to support the 783 vagus-mediated action of AM6545, we found a stark increase of cFos, a marker of 784 neuronal activity, in key brain regions of the satietogenic neuronal pathway. 785 Importantly, we reveal that blockade of peripheral CB1R signaling resulted in a 786 strong vagus-dependent activation of the NTS as well as of its downstream 787 connected structures, notably the IPBN and the hypothalamic PVN. This segmented 788 activation of the gut $\rightarrow$ brainstem $\rightarrow$ hypothalamus path is most likely responsible for 789 the AM6545-induced effects on bingeing and energy homeostasis since structure790 specific activation of these nodes has been shown to reduce food intake and alter 791 energy homeostasis (An et al., 2020; Campos et al., 2016; Carter et al., 2013; 792 D'Agostino et al., 2016; Li et al., 2019a, 2019b; Roman et al., 2016). In addition to 793 this satietogenic path and given the strong reward component of our time-locked feeding paradigm, we also uncover that AM6545-mediated vagus activation results in a dampened activation of VTA DA-neurons. In fact, peripheral blockade of CB1R also resulted in a stark blunting of the DA-dependent GBR-evoked increased locomotor activity and DA-mediated cFos expression in the nucleus accumbens, a functional output that requires the intact vagal gut-brain axis. However, such effect did not depend on the releasing capabilities of DA neurons since AM6545 failed in altering amphetamine-evoked locomotor activity. In addition, taking advantage of virally mediated GCaMP6f-evoked in vivo $\mathrm{Ca}^{2+}$ imaging of putative VTA DA-neurons (Anzalone et al., 2012; Bello et al., 2011), here we demonstrate that peripheral blockade of CB1R clearly reduces both basal and evoked activity of DA-neurons, a feature resembling the effects of vagal nerve stimulation (Manta et al., 2013; Perez et al., 2014).

806 The VTA has a heterogeneous connectivity (Morales and Margolis, 2017) and a 807 single and monosynaptic circuit responsible for the inhibition DA-neurons through the 808 AM6545-activated vagus nerve cannot be selectively sorted out yet. However, 809 several satiety-related structures in the brainstem, hindbrain and hypothalamus are 810 known to project and modulate, directly or indirectly, VTA DA-neurons (Alhadeff et 811 al., 2012; Boughter et al., 2019; Faget et al., 2016; Grill and Hayes, 2012; Han et al., 812 2018; Nieh et al., 2016; Wang et al., 2015). Among these circuits, the PBN $\rightarrow$ VTA 813 relay is of particular interest since excitatory PBN neurons also largely contact VTA 814 GABA-neurons (Beier et al., 2015; Faget et al., 2016) which in turn may drive the 
815 inhibition of VTA DA-neurons and consequent dampening of motivated 816 behaviors.

817

818 Here, we show that DA-dependent adaptations require orchestrated inputs 819 among which peripheral endocannabinoids, through the vagus nerve, allostatically 820 scale the homeostatic and hedonic components of feeding and act as mandatory 821 gatekeepers for adaptive responses of the reward circuit. Indeed, the gut-brain axis is 822 increasingly incriminated as a key player of the regulation of energy metabolism 823 (Clemmensen et al., 2017), and we show for the first time that BE is under the control 824 of the vagus-mediated peripheral inputs. Pointing the peripheral eCBs as permissive 825 actors of this eating disorder certainly brings novelty in the clinical investigations 826 aimed at identifying innovative and non-invasive therapeutic strategies. Importantly, 827 this study further points the gut-brain axis as privileged target to modulate brain 828 structures that are functionally responsible for processing integrative cognitive and 829 reward.

830 In conclusion, while further studies are warrant to fully untangle the key enteric actors 831 responsible for this phenomenon, our study identifies a novel integrative mechanism 832 by which peripheral endocannabinoids through the vagal gut-brain axis gate allostatic 833 feeding by controlling satiety and reward events, thus also paving the way to target 834 peripheral elements for brain disorders. 


\section{Acknowledgments}

836 We thank Chloé Morel, Rim Hassouna, Anne-Sophie Delbes, Daniela Herrera Moro

837 and Raphaël Denis for technical advice and support. Adrien Paquot

838 (BPBL/UCLouvain) is acknowledged for its help with eCB quantification. We thank 839 Olja Kacanski for administrative support, Isabelle Le Parco, Ludovic Maingault, 840 Angélique Dauvin, Aurélie Djemat, Florianne Michel, Magguy Boa and Daniel 841 Quintas for animals' care and Sabria Allithi for genotyping. We acknowledge the 842 technical platform Functional and Physiological Exploration platform (FPE) of the 843 Université de Paris (BFA - UMR 8251) and the animal core facility Buffon of the 844 Université de Paris/Institut Jacques Monod. This work was supported by the Fyssen 845 Foundation, Nutricia Research Foundation, Allen Foundation Inc., Université de Paris 846 and CNRS. CB and EM were supported by fellowships from the Fondation pour la 847 Recherche Médicale (FRM).

848

849 Author Contributions

850 C.B. and G.G. conceived, designed, performed and analyzed most of the 851 experiments. J.C. performed surgeries and behavioral experiments. E.M. helped with 852 molecular studies. E.F. performed vagotomy. C.M. helped with fiber photometry 853 experiments. G.G.M. analyzed endocannabinoids levels. S.L. provided scientific 854 guidance and critical feedback. S.L. and G.G. secured funding. G.G. supervised the 855 whole project, interpreted the data and wrote the manuscript with contribution from all 856 coauthors.

857

\section{Declaration of Interests}

859 The authors declare no competing interests. 


\section{References}

861 Alhadeff, A.L., Rupprecht, L.E., and Hayes, M.R. (2012). GLP-1 neurons in the 862 nucleus of the solitary tract project directly to the ventral tegmental area and nucleus 863 accumbens to control for food intake. Endocrinology 153, 647-658.

864 Alhadeff, A.L., Goldstein, N., Park, O., Klima, M.L., Vargas, A., and Betley, J.N. 865 (2019). Natural and Drug Rewards Engage Distinct Pathways that Converge on 866 Coordinated Hypothalamic and Reward Circuits. Neuron 103, 891-908.e6.

867 An, J.J., Kinney, C.E., Tan, J.-W., Liao, G.-Y., Kremer, E.J., and Xu, B. (2020). TrkB868 expressing paraventricular hypothalamic neurons suppress appetite through multiple neurocircuits. Nat Commun 11, 1729.

Anzalone, A., Lizardi-Ortiz, J.E., Ramos, M., De Mei, C., Hopf, F.W., laccarino, C., Halbout, B., Jacobsen, J., Kinoshita, C., Welter, M., et al. (2012). Dual control of dopamine synthesis and release by presynaptic and postsynaptic dopamine D2 receptors. J Neurosci 32, 9023-9034.

de Araujo, I.E., Schatzker, M., and Small, D.M. (2020). Rethinking Food Reward. Annual Review of Psychology 71, 139-164.

Arch, J.R.S., Hislop, D., Wang, S.J.Y., and Speakman, J.R. (2006). Some mathematical and technical issues in the measurement and interpretation of opencircuit indirect calorimetry in small animals. Int J Obes (Lond) 30, 1322-1331.

Argueta, D.A., and DiPatrizio, N.V. (2017). Peripheral endocannabinoid signaling controls hyperphagia in western diet-induced obesity. Physiol Behav 171, 32-39.

Argueta, D.A., Perez, P.A., Makriyannis, A., and DiPatrizio, N.V. (2019). Cannabinoid CB1 Receptors Inhibit Gut-Brain Satiation Signaling in Diet-Induced Obesity. Front Physiol 10, 704.

Avena, N.M. (2010). The study of food addiction using animal models of binge eating. Appetite 55, 734-737.

Bai, L., Mesgarzadeh, S., Ramesh, K.S., Huey, E.L., Liu, Y., Gray, L.A., Aitken, T.J., Chen, Y., Beutler, L.R., Ahn, J.S., et al. (2019). Genetic Identification of Vagal Sensory Neurons That Control Feeding. Cell 179, 1129-1143.e23.

Bake, T., Murphy, M., Morgan, D.G.A., and Mercer, J.G. (2014). Large, binge-type meals of high fat diet change feeding behaviour and entrain food anticipatory activity in mice. Appetite 77, 60-71.

Balodis, I.M., Grilo, C.M., and Potenza, M.N. (2015). Neurobiological features of binge eating disorder. CNS Spectr 20, 557-565.

Beaulieu, J.-M., and Gainetdinov, R.R. (2011). The physiology, signaling, and pharmacology of dopamine receptors. Pharmacol. Rev. 63, 182-217.

Beier, K.T., Steinberg, E.E., DeLoach, K.E., Xie, S., Miyamichi, K., Schwarz, L., Gao, X.J., Kremer, E.J., Malenka, R.C., and Luo, L. (2015). Circuit Architecture of VTA Dopamine Neurons Revealed by Systematic Input-Output Mapping. Cell 162, 622634.

Bello, E.P., Mateo, Y., Gelman, D.M., Noaín, D., Shin, J.H., Low, M.J., Alvarez, V.A., Lovinger, D.M., and Rubinstein, M. (2011). Cocaine supersensitivity and enhanced motivation for reward in mice lacking dopamine D2 autoreceptors. Nat Neurosci 14, 1033-1038.

Bellocchio, L., Soria-Gómez, E., Quarta, C., Metna-Laurent, M., Cardinal, P., Binder, E., Cannich, A., Delamarre, A., Häring, M., Martín-Fontecha, M., et al. (2013). Activation of the sympathetic nervous system mediates hypophagic and anxiety-like effects of $\mathrm{CB}_{1}$ receptor blockade. Proc Natl Acad Sci U S A 110, 4786-4791.

Berthoud, H.-R., Münzberg, H., and Morrison, C.D. (2017). Blaming the Brain for Obesity: Integration of Hedonic and Homeostatic Mechanisms. Gastroenterology 
910 152, 1728-1738.

911 Bertran-Gonzalez, J., Bosch, C., Maroteaux, M., Matamales, M., Hervé, D., Valjent, 912 E., and Girault, J.-A. (2008). Opposing patterns of signaling activation in dopamine 913 D1 and D2 receptor-expressing striatal neurons in response to cocaine and 914 haloperidol. J. Neurosci. 28, 5671-5685.

915 Beutler, L.R., Corpuz, T.V., Ahn, J.S., Kosar, S., Song, W., Chen, Y., and Knight, 916 Z.A. (2020). Obesity causes selective and long-lasting desensitization of AgRP 917 neurons to dietary fat. Elife 9.

918 Biever, A., Puighermanal, E., Nishi, A., David, A., Panciatici, C., Longueville, S., 919 Xirodimas, D., Gangarossa, G., Meyuhas, O., Hervé, D., et al. (2015). PKA920 dependent phosphorylation of ribosomal protein S6 does not correlate with 921 translation efficiency in striatonigral and striatopallidal medium-sized spiny neurons. 922 J. Neurosci. 35, 4113-4130.

923 Bohórquez, D.V., Samsa, L.A., Roholt, A., Medicetty, S., Chandra, R., and Liddle, 924 R.A. (2014). An enteroendocrine cell-enteric glia connection revealed by 3D electron 925 microscopy. PLoS One 9, e89881.

926 Bohórquez, D.V., Shahid, R.A., Erdmann, A., Kreger, A.M., Wang, Y., Calakos, N., 927 Wang, F., and Liddle, R.A. (2015). Neuroepithelial circuit formed by innervation of sensory enteroendocrine cells. J Clin Invest 125, 782-786.

Boon, M.R., Kooijman, S., van Dam, A.D., Pelgrom, L.R., Berbée, J.F.P., Visseren, C.A.R., van Aggele, R.C., van den Hoek, A.M., Sips, H.C.M., Lombès, M., et al. (2014). Peripheral cannabinoid 1 receptor blockade activates brown adipose tissue and diminishes dyslipidemia and obesity. FASEB J 28, 5361-5375.

Bottemanne, P., Paquot, A., Ameraoui, H., Alhouayek, M., and Muccioli, G.G. (2019). The $\alpha / \beta$-hydrolase domain 6 inhibitor WWL70 decreases endotoxin-induced lung inflammation in mice, potential contribution of 2-arachidonoylglycerol, and lysoglycerophospholipids. FASEB J 33, 7635-7646.

937 Boughter, J.D., Lu, L., Saites, L.N., and Tokita, K. (2019). Sweet and bitter taste 938 stimuli activate VTA projection neurons in the parabrachial nucleus. Brain Res 1714, 939 99-110.

940 Burdyga, G., Varro, A., Dimaline, R., Thompson, D.G., and Dockray, G.J. (2010). Expression of cannabinoid CB1 receptors by vagal afferent neurons: kinetics and role in influencing neurochemical phenotype. Am J Physiol Gastrointest Liver Physiol 299, G63-69.

Campos, C.A., Bowen, A.J., Schwartz, M.W., and Palmiter, R.D. (2016). Parabrachial CGRP Neurons Control Meal Termination. Cell Metab 23, 811-820.

Capasso, A., Milano, W., and Cauli, O. (2018). Changes in the Peripheral Endocannabinoid System as a Risk Factor for the Development of Eating Disorders. Endocr Metab Immune Disord Drug Targets 18, 325-332.

Caravaggio, F., Raitsin, S., Gerretsen, P., Nakajima, S., Wilson, A., and GraffGuerrero, A. (2015). Ventral striatum binding of a dopamine D2/3 receptor agonist but not antagonist predicts normal body mass index. Biol Psychiatry 77, 196-202.

Carr, M.M., and Grilo, C.M. (2020). Examining heterogeneity of binge-eating disorder using latent class analysis. J Psychiatr Res 130, 194-200.

Carter, M.E., Soden, M.E., Zweifel, L.S., and Palmiter, R.D. (2013). Genetic identification of a neural circuit that suppresses appetite. Nature 503, 111-114.

Cheng, W., Gonzalez, I., Pan, W., Tsang, A.H., Adams, J., Ndoka, E., Gordian, D., Khoury, B., Roelofs, K., Evers, S.S., et al. (2020). Calcitonin Receptor Neurons in the Mouse Nucleus Tractus Solitarius Control Energy Balance via the Non-aversive Suppression of Feeding. Cell Metab 31, 301-312.e5. 
960 Clemmensen, C., Müller, T.D., Woods, S.C., Berthoud, H.-R., Seeley, R.J., and 961 Tschöp, M.H. (2017). Gut-Brain Cross-Talk in Metabolic Control. Cell 168, 758-774.

962 Cluny, N.L., Vemuri, V.K., Chambers, A.P., Limebeer, C.L., Bedard, H., Wood, J.T.,

963 Lutz, B., Zimmer, A., Parker, L.A., Makriyannis, A., et al. (2010). A novel peripherally 964 restricted cannabinoid receptor antagonist, AM6545, reduces food intake and body 965 weight, but does not cause malaise, in rodents. Br J Pharmacol 161, 629-642.

966 Coll, A.P., Farooqi, I.S., and O'Rahilly, S. (2007). The hormonal control of food 967 intake. Cell 129, 251-262.

968 Cone, J.J., McCutcheon, J.E., and Roitman, M.F. (2014). Ghrelin acts as an interface 969 between physiological state and phasic dopamine signaling. J Neurosci 34, 49059704913.

971 D’Agostino, G., Lyons, D.J., Cristiano, C., Burke, L.K., Madara, J.C., Campbell, J.N., 972 Garcia, A.P., Land, B.B., Lowell, B.B., Dileone, R.J., et al. (2016). Appetite controlled 973 by a cholecystokinin nucleus of the solitary tract to hypothalamus neurocircuit. Elife 9745.

975 De Ridder, D., Manning, P., Leong, S.L., Ross, S., and Vanneste, S. (2016). 976 Allostasis in health and food addiction. Sci Rep 6, 37126.

977 DiFeliceantonio, A.G., Coppin, G., Rigoux, L., Edwin Thanarajah, S., Dagher, A., 978 Tittgemeyer, M., and Small, D.M. (2018). Supra-Additive Effects of Combining Fat and Carbohydrate on Food Reward. Cell Metab 28, 33-44.e3.

DiPatrizio, N.V., and Piomelli, D. (2015). Intestinal lipid-derived signals that sense dietary fat. J Clin Invest 125, 891-898.

DiPatrizio, N.V., Joslin, A., Jung, K.-M., and Piomelli, D. (2013). Endocannabinoid signaling in the gut mediates preference for dietary unsaturated fats. FASEB $\mathrm{J} 27$, 2513-2520.

Egerod, K.L., Petersen, N., Timshel, P.N., Rekling, J.C., Wang, Y., Liu, Q., Schwartz, T.W., and Gautron, L. (2018). Profiling of $G$ protein-coupled receptors in vagal afferents reveals novel gut-to-brain sensing mechanisms. Mol Metab 12, 62-75.

Even, P.C., and Nadkarni, N.A. (2012). Indirect calorimetry in laboratory mice and rats: principles, practical considerations, interpretation and perspectives. Am J Physiol Regul Integr Comp Physiol 303, R459-476.

Faget, L., Osakada, F., Duan, J., Ressler, R., Johnson, A.B., Proudfoot, J.A., Yoo, J.H., Callaway, E.M., and Hnasko, T.S. (2016). Afferent Inputs to NeurotransmitterDefined Cell Types in the Ventral Tegmental Area. Cell Rep 15, 2796-2808.

Fernandes, A.B., Alves da Silva, J., Almeida, J., Cui, G., Gerfen, C.R., Costa, R.M., and Oliveira-Maia, A.J. (2020). Postingestive Modulation of Food Seeking Depends on Vagus-Mediated Dopamine Neuron Activity. Neuron 106, 778-788.e6.

Fulton, S., Pissios, P., Manchon, R.P., Stiles, L., Frank, L., Pothos, E.N., MaratosFlier, E., and Flier, J.S. (2006). Leptin regulation of the mesoaccumbens dopamine pathway. Neuron 51, 811-822.

Gangarossa, G., Perroy, J., and Valjent, E. (2013a). Combinatorial topography and cell-type specific regulation of the ERK pathway by dopaminergic agonists in the mouse striatum. Brain Struct Funct 218, 405-419.

Gangarossa, G., Espallergues, J., de Kerchove d'Exaerde, A., El Mestikawy, S., Gerfen, C.R., Hervé, D., Girault, J.-A., and Valjent, E. (2013b). Distribution and compartmental organization of GABAergic medium-sized spiny neurons in the mouse nucleus accumbens. Front Neural Circuits 7, 22.

Gangarossa, G., Castell, L., Castro, L., Tarot, P., Veyrunes, F., Vincent, P., Bertaso, F., and Valjent, E. (2019). Contrasting patterns of ERK activation in the tail of the striatum in response to aversive and rewarding signals. J. Neurochem. 151, 204- 
1010226.

1011 George, O., Le Moal, M., and Koob, G.F. (2012). Allostasis and addiction: role of the

1012 dopamine and corticotropin-releasing factor systems. Physiol Behav 106, 58-64.

1013 Glass, L.L., Calero-Nieto, F.J., Jawaid, W., Larraufie, P., Kay, R.G., Göttgens, B., 1014 Reimann, F., and Gribble, F.M. (2017). Single-cell RNA-sequencing reveals a distinct 1015 population of proglucagon-expressing cells specific to the mouse upper small 1016 intestine. Mol Metab 6, 1296-1303.

1017 Godlewski, G., Cinar, R., Coffey, N.J., Liu, J., Jourdan, T., Mukhopadhyay, B., 1018 Chedester, L., Liu, Z., Osei-Hyiaman, D., lyer, M.R., et al. (2019). Targeting 1019 Peripheral CB1 Receptors Reduces Ethanol Intake via a Gut-Brain Axis. Cell Metab 1020 29, 1320-1333.e8.

1021 Gómez, R., Navarro, M., Ferrer, B., Trigo, J.M., Bilbao, A., Del Arco, I., Cippitelli, A., Nava, F., Piomelli, D., and Rodríguez de Fonseca, F. (2002). A peripheral mechanism for CB1 cannabinoid receptor-dependent modulation of feeding. J Neurosci 22, 9612-9617.

1025

1026

1027

Gore, B.B., and Zweifel, L.S. (2013). Genetic reconstruction of dopamine D1 receptor signaling in the nucleus accumbens facilitates natural and drug reward responses. J Neurosci 33, 8640-8649.

1028 Gribble, F.M., and Reimann, F. (2019). Function and mechanisms of enteroendocrine cells and gut hormones in metabolism. Nat Rev Endocrinol 15, $226-237$.

Grill, H.J., and Hayes, M.R. (2012). Hindbrain neurons as an essential hub in the neuroanatomically distributed control of energy balance. Cell Metab 16, 296-309.

Haber, A.L., Biton, M., Rogel, N., Herbst, R.H., Shekhar, K., Smillie, C., Burgin, G., Delorey, T.M., Howitt, M.R., Katz, Y., et al. (2017). A single-cell survey of the small intestinal epithelium. Nature 551, 333-339.

Han, W., Tellez, L.A., Niu, J., Medina, S., Ferreira, T.L., Zhang, X., Su, J., Tong, J., Schwartz, G.J., van den Pol, A., et al. (2016). Striatal Dopamine Links Gastrointestinal Rerouting to Altered Sweet Appetite. Cell Metab 23, 103-112.

1038 Han, W., Tellez, L.A., Perkins, M.H., Perez, I.O., Qu, T., Ferreira, J., Ferreira, T.L., 1039 Quinn, D., Liu, Z.-W., Gao, X.-B., et al. (2018). A Neural Circuit for Gut-Induced Reward. Cell 175, 665-678.e23.

Hankir, M.K., Seyfried, F., Hintschich, C.A., Diep, T.-A., Kleberg, K., Kranz, M., Deuther-Conrad, W., Tellez, L.A., Rullmann, M., Patt, M., et al. (2017). Gastric Bypass Surgery Recruits a Gut PPAR- $\alpha$-Striatal D1R Pathway to Reduce Fat Appetite in Obese Rats. Cell Metab. 25, 335-344.

Hutson, P.H., Balodis, I.M., and Potenza, M.N. (2018). Binge-eating disorder: Clinical and therapeutic advances. Pharmacol Ther 182, 15-27.

Izzo, A.A., Piscitelli, F., Capasso, R., Aviello, G., Romano, B., Borrelli, F., Petrosino, S., and Di Marzo, V. (2009). Peripheral endocannabinoid dysregulation in obesity: relation to intestinal motility and energy processing induced by food deprivation and re-feeding. Br J Pharmacol 158, 451-461.

1050

1051

1052

1053

1054

1055

1056

1057

1058

1059 Jerlhag, E., Egecioglu, E., Dickson, S.L., Douhan, A., Svensson, L., and Engel, J.A. (2007). Ghrelin administration into tegmental areas stimulates locomotor activity and increases extracellular concentration of dopamine in the nucleus accumbens. Addict Biol 12, 6-16.

Kaelberer, M.M., Buchanan, K.L., Klein, M.E., Barth, B.B., Montoya, M.M., Shen, X., and Bohórquez, D.V. (2018). A gut-brain neural circuit for nutrient sensory transduction. Science 361.

Kai, N., Nishizawa, K., Tsutsui, Y., Ueda, S., and Kobayashi, K. (2015). Differential roles of dopamine D1 and D2 receptor-containing neurons of the nucleus accumbens 
1060 shell in behavioral sensitization. J Neurochem 135, 1232-1241.

1061 Kenny, P.J., Voren, G., and Johnson, P.M. (2013). Dopamine D2 receptors and 1062 striatopallidal transmission in addiction and obesity. Curr Opin Neurobiol 23, 535-

\section{8.}

1064 Keramati, M., and Gutkin, B. (2014). Homeostatic reinforcement learning for 1065 integrating reward collection and physiological stability. Elife 3.

1066 Kobayashi, T., Araki, T., Itoyama, Y., Takeshita, M., Ohta, T., and Oshima, Y. (1997). 1067 Effects of L-dopa and bromocriptine on haloperidol-induced motor deficits in mice. 1068 Life Sci 61, 2529-2538.

1069 Kolata, S.M., Nakao, K., Jeevakumar, V., Farmer-Alroth, E.L., Fujita, Y., Bartley, 1070 A.F., Jiang, S.Z., Rompala, G.R., Sorge, R.E., Jimenez, D.V., et al. (2018). 1071 Neuropsychiatric Phenotypes Produced by GABA Reduction in Mouse Cortex and Hippocampus. Neuropsychopharmacology 43, 1445-1456.

1073 Kuipers, E.N., Kantae, V., Maarse, B.C.E., van den Berg, S.M., van Eenige, R., 1074 Nahon, K.J., Reifel-Miller, A., Coskun, T., de Winther, M.P.J., Lutgens, E., et al. 1075 (2018). High Fat Diet Increases Circulating Endocannabinoids Accompanied by 1076 Increased Synthesis Enzymes in Adipose Tissue. Front Physiol 9, 1913.

1077 Ladenheim, E.E. (2015). Liraglutide and obesity: a review of the data so far. Drug 1078 Des Devel Ther 9, 1867-1875.

1079 de Lartigue, G. (2016). Role of the vagus nerve in the development and treatment of diet-induced obesity. J Physiol 594, 5791-5815.

Lau, B.K., Cota, D., Cristino, L., and Borgland, S.L. (2017). Endocannabinoid modulation of homeostatic and non-homeostatic feeding circuits. Neuropharmacology 124, 38-51.

Lenard, N.R., and Berthoud, H.-R. (2008). Central and peripheral regulation of food intake and physical activity: pathways and genes. Obesity (Silver Spring) 16 Suppl 3, S11-22.

1087 Lerner, T.N., Shilyansky, C., Davidson, T.J., Evans, K.E., Beier, K.T., Zalocusky, 1088 K.A., Crow, A.K., Malenka, R.C., Luo, L., Tomer, R., et al. (2015). Intact-Brain 1089 Analyses Reveal Distinct Information Carried by SNc Dopamine Subcircuits. Cell 1090 162, 635-647.

1091 Li, C., Navarrete, J., Liang-Guallpa, J., Lu, C., Funderburk, S.C., Chang, R.B., Liberles, S.D., Olson, D.P., and Krashes, M.J. (2019a). Defined Paraventricular Hypothalamic Populations Exhibit Differential Responses to Food Contingent on Caloric State. Cell Metab 29, 681-694.e5.

Li, M.M., Madara, J.C., Steger, J.S., Krashes, M.J., Balthasar, N., Campbell, J.N., Resch, J.M., Conley, N.J., Garfield, A.S., and Lowell, B.B. (2019b). The Paraventricular Hypothalamus Regulates Satiety and Prevents Obesity via Two Genetically Distinct Circuits. Neuron 102, 653-667.e6. induces time-dependent synaptic plasticity of the lateral hypothalamus. Mol Metab 36, 100977.

1102

Long, J.Z., Li, W., Booker, L., Burston, J.J., Kinsey, S.G., Schlosburg, J.E., Pavón, F.J., Serrano, A.M., Selley, D.E., Parsons, L.H., et al. (2009). Selective blockade of 2 -arachidonoylglycerol hydrolysis produces cannabinoid behavioral effects. Nat Chem Biol 5, 37-44.

Luo, Z., Volkow, N.D., Heintz, N., Pan, Y., and Du, C. (2011). Acute cocaine induces fast activation of D1 receptor and progressive deactivation of D2 receptor striatal neurons: in vivo optical microprobe [Ca2+]i imaging. J Neurosci 31, 13180-13190. 
1110 regulation of food intake. J Nutr 139, 629-632.

1111

1112

1113

1114

1115

1116

1117

1118

1119

1120

1121

1122

1123

1124

1125

1126

1127

1128

1129

1130

1131

1132

1133

1134

1135

1136

1137

1138

1139

1140

1141

1142

1143

1144

1145

1146

1147

1148

1149

1150

1151

1152

1153

1154

1155

1156

1157

1158

1159

Malbert, C.-H., Genissel, M., Divoux, J.-L., and Henry, C. (2019). Chronic abdominal vagus stimulation increased brain metabolic connectivity, reduced striatal dopamine transporter and increased mid-brain serotonin transporter in obese miniature pigs. J Transl Med 17, 78.

Manta, S., El Mansari, M., Debonnel, G., and Blier, P. (2013). Electrophysiological and neurochemical effects of long-term vagus nerve stimulation on the rat monoaminergic systems. Int J Neuropsychopharmacol 16, 459-470.

Mazier, W., Saucisse, N., Simon, V., Cannich, A., Marsicano, G., Massa, F., and Cota, D. (2019). mTORC1 and CB1 receptor signaling regulate excitatory glutamatergic inputs onto the hypothalamic paraventricular nucleus in response to energy availability. Mol Metab 28, 151-159.

McEwen, B.S., and Wingfield, J.C. (2003). The concept of allostasis in biology and biomedicine. Horm Behav 43, 2-15.

Michaelides, M., Thanos, P.K., Kim, R., Cho, J., Ananth, M., Wang, G.-J., and Volkow, N.D. (2012). PET imaging predicts future body weight and cocaine preference. Neuroimage 59, 1508-1513.

Monteleone, A.M., Di Marzo, V., Monteleone, P., Dalle Grave, R., Aveta, T., Ghoch, M.E., Piscitelli, F., Volpe, U., Calugi, S., and Maj, M. (2016). Responses of peripheral endocannabinoids and endocannabinoid-related compounds to hedonic eating in obesity. Eur J Nutr 55, 1799-1805.

Monteleone, A.M., Piscitelli, F., Dalle Grave, R., El Ghoch, M., Di Marzo, V., Maj, M., and Monteleone, P. (2017). Peripheral Endocannabinoid Responses to Hedonic Eating in Binge-Eating Disorder. Nutrients 9.

Monteleone, P., Matias, I., Martiadis, V., De Petrocellis, L., Maj, M., and Di Marzo, V. (2005). Blood levels of the endocannabinoid anandamide are increased in anorexia nervosa and in binge-eating disorder, but not in bulimia nervosa. Neuropsychopharmacology 30,1216-1221.

Morales, M., and Margolis, E.B. (2017). Ventral tegmental area: cellular heterogeneity, connectivity and behaviour. Nat Rev Neurosci 18, 73-85.

Muñoz-Escobar, G., Guerrero-Vargas, N.N., and Escobar, C. (2019). Random access to palatable food stimulates similar addiction-like responses as a fixed schedule, but only a fixed schedule elicits anticipatory activation. Sci Rep 9, 18223.

Naish, K.R., Laliberte, M., MacKillop, J., and Balodis, I.M. (2019). Systematic review of the effects of acute stress in binge eating disorder. Eur J Neurosci 50, 2415-2429.

Nieh, E.H., Vander Weele, C.M., Matthews, G.A., Presbrey, K.N., Wichmann, R., Leppla, C.A., Izadmehr, E.M., and Tye, K.M. (2016). Inhibitory Input from the Lateral Hypothalamus to the Ventral Tegmental Area Disinhibits Dopamine Neurons and Promotes Behavioral Activation. Neuron 90, 1286-1298.

Oosterman, J.E., Koekkoek, L.L., Foppen, E., Unmehopa, U.A., Eggels, L., Verheij, J., Fliers, E., la Fleur, S.E., and Kalsbeek, A. (2020). Synergistic Effect of Feeding Time and Diet on Hepatic Steatosis and Gene Expression in Male Wistar Rats. Obesity (Silver Spring) 28 Suppl 1, S81-S92.

Palmiter, R.D. (2007). Is dopamine a physiologically relevant mediator of feeding behavior? Trends Neurosci 30, 375-381.

Perez, S.M., Carreno, F.R., Frazer, A., and Lodge, D.J. (2014). Vagal nerve stimulation reverses aberrant dopamine system function in the methylazoxymethanol acetate rodent model of schizophrenia. J Neurosci 34, 9261-9267.

Quarta, C., Mazza, R., Obici, S., Pasquali, R., and Pagotto, U. (2011). Energy balance regulation by endocannabinoids at central and peripheral levels. Trends $\mathrm{Mol}$ 
1160 Med 17, 518-526.

1161 Rada, P., Avena, N.M., and Hoebel, B.G. (2005). Daily bingeing on sugar repeatedly

1162 releases dopamine in the accumbens shell. Neuroscience 134, 737-744.

1163 Radl, D., Chiacchiaretta, M., Lewis, R.G., Brami-Cherrier, K., Arcuri, L., and Borrelli, 1164 E. (2018). Differential regulation of striatal motor behavior and related cellular responses by dopamine D2L and D2S isoforms. Proc Natl Acad Sci U S A 115, 198203.

Ramsay, D.S., and Woods, S.C. (2014). Clarifying the roles of homeostasis and allostasis in physiological regulation. Psychol Rev 121, 225-247.

Reddy, I.A., Smith, N.K., Erreger, K., Ghose, D., Saunders, C., Foster, D.J., Turner, B., Poe, A., Albaugh, V.L., McGuinness, O., et al. (2018). Bile diversion, a bariatric surgery, and bile acid signaling reduce central cocaine reward. PLoS Biol 16, e2006682.

Reichelt, A.C., Westbrook, R.F., and Morris, M.J. (2015). Integration of reward signalling and appetite regulating peptide systems in the control of food-cue responses. Br J Pharmacol 172, 5225-5238.

1176

1177

1178

1179

1180

1181

1182 Roman, C.W., Derkach, V.A., and Palmiter, R.D. (2016). Genetically and functionally defined NTS to PBN brain circuits mediating anorexia. Nat Commun 7, 11905.

Rossi, M.A., and Stuber, G.D. (2018). Overlapping Brain Circuits for Homeostatic and Hedonic Feeding. Cell Metab. 27, 42-56.

Rossi, M.A., Basiri, M.L., McHenry, J.A., Kosyk, O., Otis, J.M., van den Munkhof, H.E., Bryois, J., Hübel, C., Breen, G., Guo, W., et al. (2019). Obesity remodels activity and transcriptional state of a lateral hypothalamic brake on feeding. Science 364, 1271-1274.

Saper, C.B., Chou, T.C., and Elmquist, J.K. (2002). The need to feed: homeostatic and hedonic control of eating. Neuron 36, 199-211.

Small, D.M., Jones-Gotman, M., and Dagher, A. (2003). Feeding-induced dopamine release in dorsal striatum correlates with meal pleasantness ratings in healthy human volunteers. Neuroimage 19, 1709-1715.

1189 Spierling, S., de Guglielmo, G., Kirson, D., Kreisler, A., Roberto, M., George, O., and Zorrilla, E.P. (2020). Insula to ventral striatal projections mediate compulsive eating produced by intermittent access to palatable food. Neuropsychopharmacology 45 , 579-588.

Sutton, L.P., and Caron, M.G. (2015). Essential role of D1R in the regulation of mTOR complex1 signaling induced by cocaine. Neuropharmacology 99, 610-619.

Sykaras, A.G., Demenis, C., Case, R.M., McLaughlin, J.T., and Smith, C.P. (2012). Duodenal enteroendocrine l-cells contain mRNA transcripts encoding key endocannabinoid and fatty acid receptors. PLoS One 7, e42373. Watanabe, M., Smith, C.C., Fernández, G., Deisseroth, K., Greene, R.W., et al. (2016). Locus coeruleus and dopaminergic consolidation of everyday memory. Nature 537, 357-362.

Tam, J., Vemuri, V.K., Liu, J., Bátkai, S., Mukhopadhyay, B., Godlewski, G., OseiHyiaman, D., Ohnuma, S., Ambudkar, S.V., Pickel, J., et al. (2010). Peripheral CB1 cannabinoid receptor blockade improves cardiometabolic risk in mouse models of obesity. J Clin Invest 120, 2953-2966. T.T., Schwartz, G.J., and de Araujo, I.E. (2013). A gut lipid messenger links excess dietary fat to dopamine deficiency. Science 341, 800-802. 
1210 van den Pol, A.N., and de Araujo, I.E. (2016). Separate circuitries encode the hedonic and nutritional values of sugar. Nat Neurosci 19, 465-470. Usiello, A., Baik, J.H., Rougé-Pont, F., Picetti, R., Dierich, A., LeMeur, M., Piazza, P.V., and Borrelli, E. (2000). Distinct functions of the two isoforms of dopamine D2 receptors. Nature 408, 199-203.

1215 Valjent, E., Biever, A., Gangarossa, G., and Puighermanal, E. (2019). Dopamine signaling in the striatum. In Advances in Protein Chemistry and Structural Biology, (Academic Press), p.

1218 Wang, G.-J., Geliebter, A., Volkow, N.D., Telang, F.W., Logan, J., Jayne, M.C., Galanti, K., Selig, P.A., Han, H., Zhu, W., et al. (2011). Enhanced striatal dopamine release during food stimulation in binge eating disorder. Obesity (Silver Spring) 19, 1601-1608.

Wang, X.-F., Liu, J.-J., Xia, J., Liu, J., Mirabella, V., and Pang, Z.P. (2015). Endogenous Glucagon-like Peptide-1 Suppresses High-Fat Food Intake by Reducing Synaptic Drive onto Mesolimbic Dopamine Neurons. Cell Rep 12, 726-733. Wei, W., Pham, K., Gammons, J.W., Sutherland, D., Liu, Y., Smith, A., Kaczorowski, C.C., and O'Connell, K.M.S. (2015). Diet composition, not calorie intake, rapidly alters intrinsic excitability of hypothalamic AgRP/NPY neurons in mice. Sci Rep 5, 16810.

1229

1230

Wise, R.A. (2004). Dopamine, learning and motivation. Nat. Rev. Neurosci. 5, 483494. 


\section{Figure legends}

1232

1233

1234

1235

1236

1237

1238

1239

1240

1241

1242

1243

1244

1245

1246

1247

1248

1249

1250

1251

1252

1253

1254

1255

1256

1257

1258

1259

1260

1261

1262

1263

\section{Figure 1: Allostatic adaptations of metabolic efficiency to time-locked access} to palatable diet. (A) Experimental design. Control animals (Ctr) or bingeing animals (Binge) had daily intermittent access to water or a palatable mixture for 1 hour. Regular chow pellets were provided ad libitum throughout the entire experiment. Pictures show the gut of animals after the last binge session. (B) Daily binge consumption $(\mathrm{ml})$ of palatable mixture during a 14-days protocol. Statistics: ${ }^{* * *} p<0.001$ Binge vs Control. (C) 24 hrs locomotor activity in calorimetric chambers (average of 3 consecutive days). Red dotted rectangles indicate the locomotor activity 2 hrs prior and after palatable food access. Statistics: ${ }^{*} p<0.05$ and ${ }^{* *} p<0.01$ Binge vs Control. ( $\left.\mathbf{C}^{\mathbf{1}}\right)$ Cumulative locomotor activity two hours prior and after palatable food access. Results are expressed as beam breaks (bb). Statistics: ${ }^{*} \mathrm{p}<0.05$ and ${ }^{* * *} \mathrm{p}<0.001$ Binge vs Control. (D) Temporal pattern of regular chow food intake (Fl, kcal/h) during 24 hrs (average of 3 consecutive days). Statistics: ${ }^{* *} p<0.01$ Binge vs Control. ( $\left.\mathbf{D}^{\mathbf{1}}\right)$ Cumulative chow food intake during the dark period. Statistics: ${ }^{* * *} p<0.001$ Binge vs Control. (E) 24 hrs food intake considering all calories: standard diet (SD) and palatable food (PF). Statistics: ${ }^{* *} p<0.001$ Binge(SD) vs Control(SD), ${ }^{\# \# \#} \mathrm{p}<0.001$ Binge(SD+PF) vs Binge(SD). Note: standard diet (SD), palatable food (FD). (F) Animals' body weight throughout the entire experimental procedure. (G) Longitudinal profile of the respiratory energy ratio (RER) from indirect calorimetry (average of 3 consecutive days) and $\left(\mathbf{G}^{1}\right)$ averaged RER values 2 hours prior and after palatable food access. Statistics: ${ }^{* *} p<0.01$ and ${ }^{* *} p<0.001$ Binge vs Control. $(\mathbf{H})$ Longitudinal profile of energy expenditure (EE) from indirect calorimetry (average of 3 consecutive days) and $\left(\mathbf{H}^{\mathbf{1}}\right)$ averaged EE values 2 hours prior and after palatable food access. Statistics: ${ }^{*} \mathrm{p}<0.05$ and ${ }^{* *} \mathrm{p}<0.01$ Binge vs Control. (I) Brown adipose tissue (BAT) temperature during bingeing. Statistics: ${ }^{*} p<0.05$ and ${ }^{* *} p<0.01$ Binge vs Control. (J) Real-time core temperature recording during $24 \mathrm{hrs}$ and $\left(\mathbf{J}^{\mathbf{1}}\right)$ averaged values 2 hours prior and after palatable food access. Statistics: ${ }^{* *} p<0.001$ Binge vs Control. (K) Matching locomotor activity from core temperature measurements. Statistics: ${ }^{* *} p<0.001$ Binge vs Control. For number of mice/group and statistical details see Suppl. Table 1. 
1264 Figure 2: Peripheral signals adapt to time-locked access to palatable diet. (A)

1265 Plasma triglycerides (TG), (B) insulin and (C) corticosterone levels in animals 1266 exposed to water (Control), 1h prior (Anticipation) or $1 \mathrm{~h}$ after (Consumption) access 1267 to palatable diet. Statistics: ${ }^{*} p<0.05$ and ${ }^{* *}{ }^{* *} p<0.001$ Anticipation vs Control, ${ }^{\# \#} p<0.01$ 1268 Consumption vs Anticipation. (D) Blood glucose and (E) insulin levels in animals daily 1269 exposed to water (Ctr) or palatable diet (binge) after an oral glucose tolerance test 1270 (OGTT). Statistics: * $p<0.05$ Binge vs Control only at 30 min post OGTT. ( $\mathbf{D}^{\mathbf{1}}$ and $\mathbf{E}^{\mathbf{1}}$ ) 1271 Glucose and insulin AUC, respectively. For number of mice/group and statistical 1272 details see Suppl. Table 1.

1273

Figure 3: Binge eating induces dopamine-related molecular modifications. A. 1 hour consumption of water (Ctr) or palatable diet (Anticipation, Binge) during the paradigm. On day 14, "acute" animals were exposed to palatable diet for the first time while "anticipation" animals did not receive the food-reward. (B) Punches were extracted from the dorsal striatum (DS) and nucleus accumbens (NAc) for western blotting analysis. Phosphorylated ERK1/2, ribosomal protein S6 $\operatorname{Ser}^{235 / 236}$ (P. $\mathrm{S6}^{\mathrm{S} 235 / 236}$ ) and phosphorylated ribosomal protein S6 $\mathrm{Ser}^{240 / 244}$ (P-S6 ${ }^{\mathrm{S} 240 / 244}$ ) expression in the DS and NAc (C). (D, E) Protein quantification of phospho-ERK, $\mathrm{S6}^{\mathrm{S} 235 / 236}$ and S6 ${ }^{\mathrm{S} 240 / 244}$ in the DS (D) and NAC (E). Statistics: ${ }^{*} \mathrm{p}<0.05$, ${ }^{* *} \mathrm{p}<0.01$ and ${ }^{* * *} \mathrm{p}<0.001$ Binge or Anticipation vs Control. (F, G) Immunolabeling and quantification of phosphorylated rpS6 in the DS (F) and NAc (G) in control and binge animals. Statistics: ${ }^{* *} p<0.001$ Binge vs Control. For number of mice/group and statistical details see Suppl. Table 1.

Figure 4: Binge eating induces dopamine-related modifications in a D1Rdependent manner. (A, B) Temporal profile of locomotor activity and cumulative locomotor response $\left(\mathbf{A}^{\mathbf{1}}\right.$ and $\left.\mathbf{B}^{\mathbf{1}}\right)$ of animals treated with the dopamine-transport blocker GBR during the anticipatory phase $\left(\mathbf{A}, \mathbf{A}^{\mathbf{1}}\right)$ or one hour after intermittent access to water ( $\mathrm{Ctr}+\mathrm{GBR})$ or palatable diet (Binge $+\mathrm{GBR})\left(\mathbf{B}, \mathbf{B}^{1}\right)$. Results are expressed as beam breaks (bb). Statistics: ${ }^{* *} \mathrm{p}<0.01$ Binge+GBR vs Control+GBR.

1294 (C) Palatable diet intake after vehicle (Veh+Binge) or D1R antagonist SCH23390 (SCH+Binge) treatment. Statistics: ${ }^{* *} \mathrm{p}<0.001 \mathrm{SCH}+B i n g e$ vs Veh+Binge. (D)

1296 Palatable diet intake after vehicle (Veh+Binge) or D2R antagonist haloperidol 0.25 $1297 \mathrm{mg} / \mathrm{kg}$ or $0.5 \mathrm{mg} / \mathrm{kg}\left(\mathrm{H}^{0.25}+\right.$ Binge and $\mathrm{H}^{0.5}+$ Binge $)$ treatment. Immunolabeling of 
1298 phosphorylated rpS6 in the DS (E) and NAC (F) and their associated quantifications

$1299\left(\mathbf{E}^{\mathbf{1}}, \mathbf{E}^{\mathbf{2}}, \mathbf{F}^{\mathbf{1}}, \mathbf{F}^{\mathbf{2}}\right)$ in mice pretreated with $\mathrm{SCH} 23390$ or vehicle and exposed to time1300 locked palatable diet. Statistics: ${ }^{* \star *} \mathrm{p}<0.001$ Veh+Binge vs Veh+Control, ${ }^{\# \#} \mathrm{p}<0.001$

1301 SCH+Binge vs Veh+Binge. (G) Temporal profile of locomotor activity and cumulative 1302 locomotor response $\left(\mathbf{G}^{1}\right)$ of animals receiving $\mathrm{SCH}(\mathrm{SCH}+$ Binge) or vehicle 1303 (Veh+Binge) (red arrow) and access to palatable diet (black arrow). Statistics: $1304{ }^{* *} \mathrm{p}<0.01 \mathrm{SCH}+$ Binge vs Veh+Binge. (H) Cumulative regular chow diet intake 1305 following $\mathrm{SCH} 23390$ (SCH+Binge) or vehicle (Veh+Binge). Statistics: ${ }^{* *} \mathrm{p}<0.01$ 1306 SCH+Binge vs Veh+Binge. (I) Temporal profile of locomotor activity and cumulative 1307 locomotor response (2 hrs and $30 \mathrm{~min}, \mathbf{I}^{\mathbf{1}}$ ) induced by the D1R agonist SKF81297 1308 administered 1 hour after access to time-locked water (Ctr+SKF) or palatable diet 1309 (Binge+SKF). Statistics: ${ }^{*} p<0.05$ and ${ }^{* *} p<0.01$ Binge+SKF vs Control+SKF. For 1310 number of mice/group and statistical details see Suppl. Table 1.

1312 Figure 5: Peripheral endocannabinoids (eCBs) govern binge eating. (A) 1313 Palatable bingeing in animals pretreated with vehicle (Veh), leptin, insulin, GLP1 1314 agonists exendin-4 (Exe4) and liraglutide (Lira), CCK octapeptide sulfated (CCK-8S) 1315 or CB1R inverse agonist AM251. Statistics: ${ }^{* * *} \mathrm{p}<0.001$ Exe4-, Lira-, CCK-8S- \& 1316 AM251-treated Bingeing mice vs Veh+Binge mice, ${ }^{\# \#} \mathrm{p}<0.001$ AM251-treated vs 1317 Exe4-, Lira \& CCK-8S-treated bingeing mice. (B) Dosage of peripheral and 1318 circulating endocannabinoids: anadamide (AEA), diacylglycerol (2-AG), 1319 docosahexanoyl ethanolamide (DHEA) and oleoylethanolamide (OEA) 1 hour before 1320 and 1 hour after palatable bingeing. (C) Palatable bingeing in animals pre-treated 1321 with a single i.p. injection of vehicle (Veh), peripheral CB1R antagonist AM6545 (10 $1322 \mathrm{mg} / \mathrm{kg}$ ), and/or monoacylglycerol lipase inhibitor JZL184 (8 mg/kg). Statistics: $1323^{* * *} \mathrm{p}<0.001$ AM6545, JZL184, AM6545+JZL184 vs Veh-Binge. (D) Chronic effect of 1324 JZL184 and AM6545 on palatable bingeing. Statistics: ${ }^{* * *} p<0.001$ AM6545-Binge vs 1325 Veh-Binge, ${ }^{\# \# \#<0.001 ~ J Z L 184-B i n g e ~ v s ~ V e h-B i n g e . ~(E, ~ F) ~ E f f e c t s ~ o f ~ A M 6545 ~ o n ~}$ 1326 core temperature $(\mathbf{E})$ and locomotor activity $(\mathbf{F})$. Statistics: ${ }^{* *} p<0.01$ AM6545-Binge 1327 vs Veh-Binge. Note: black and red arrows indicate administration of AM6545 and 1328 palatable food access, respectively. (G) Longitudinal measurement of fatty acid 1329 oxidation (FAO) following administration of AM6545 during a Binge session and a 1330 NoBinge session. $\left(\mathbf{G}^{1}\right)$ Averaged FAO from time of injection (11h00) till the end of 1331 light phase (19h00). $\left(\mathbf{G}^{2}\right)$ Ratio of $F A O$ and food intake to discriminate between the 
1332 effect of AM6545 and calories intake. Statistics: ${ }^{* * *} \mathrm{p}<0.001$ AM6545 vs Veh (in both

1333 Binge and NoBinge sessions). (H) Palatable bingeing after oral gavage of AM6545 1334 (10 mg/kg, p.o.) and associated fatty acids oxidation (I). (J) The scheme indicates 1335 gut-originated afferent paths that were virally targeted to perform single-cell 1336 transcriptomic analysis (Bai et al., 2019). (K) Enrichment of different vagal markers 1337 (SLC17a6, Scn10a, Htr3a, Cartpt, Grin1, Phox2b) and comparison with Cnr1 and 1338 Cnr2 in sensory vagal neurons labeled from microinjections in the stomach, proximal 1339 and middle intestines. For number of mice/group and statistical details see Suppl. 1340 Table 1.

1342 Figure 6: The gut-brain vagal axis is required for eCBs-mediated effects. (A, B) 1343 cFos immunolabeling in the area postrema (AP), the nucleus tractus solitarius (NTS), 1344 the lateral parabrachial nucleus (IPBN) and medial parabrachial nucleus (mPBN) in 1345 sham and vagotomized animals treated with the peripheral CB1R antagonist AM6545 $1346(10 \mathrm{mg} / \mathrm{kg}) .\left(\mathbf{A}^{1}\right)$ Scheme indicates the central vagus $\rightarrow \mathrm{NTS} \rightarrow \mathrm{PBN} \rightarrow$ target regions 1347 path in VGX mice. $\left(\mathbf{A}^{2}\right)$ Quantification of cFos-positive neurons in the AP, NTS and 1348 IPBN in sham and VGX mice injected with AM6545. Statistics: ${ }^{* * *} \mathrm{p}<0.001$ 1349 VGX+AM6545 vs Sham+AM6545. (B) Palatable bingeing in sham and vagotomized 1350 (VGX) animals pre-treated with AM6545 (A) or vehicle (V), and associated 1351 measurements of fatty acid oxidation $\left(\mathbf{C}, \mathbf{C}^{\mathbf{1}}\right.$ and $\left.\mathbf{D}, \mathbf{D}^{\mathbf{1}}\right)$. Statistics: ${ }^{\star \star \star} \mathrm{p}<0.001$ 1352 Sham+AM6545 vs Sham+Veh. (E) cFos immunolabeling of paraventricular nucleus 1353 of the hypothalamus (PVN) and dormomedial nucleus of the hypothalamus (DMH) in 1354 sham or VGX animals treated with vehicle or AM5646 and associated counting ( $\mathbf{E}^{\mathbf{1}}$ ).

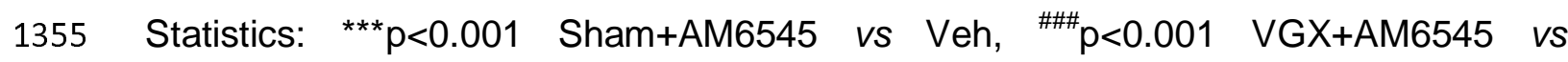
1356 Sham+AM6545. For number of mice/group and statistical details see Suppl. Table 13571.

1359 Figure 7: Peripheral CB1R signaling routed by the vagus nerve controls VTA 1360 DA-neurons activity. (A, $\mathbf{A}^{\mathbf{1}}$ ) Effect of AM6545 or Veh on GBR-induced locomotor 1361 activity (beam breaks, bb). Statistics: ${ }^{* *} \mathrm{p}<0.01$ AM6545+GBR vs Veh+GBR. (B, B ${ }^{1}$ ) 1362 Effect of AM6545 on GBR-triggered cFos in the striatum. Statistics: ${ }^{* *} p<0.001$ 1363 AM6545+GBR vs Veh+GBR. (C) Amphetamine (Amph)-induced locomotor activity 1364 and $\left(\mathbf{C}^{\mathbf{1}}\right)$ cumulative locomotor response $(\mathbf{C} 1)$ in mice pretreated with vehicle 1365 (Veh+Amph) or AM6545 (AM6545+Amph). GBR-induced locomotor activity (D), 
1366 cumulative locomotor response $\left(\mathbf{D}^{\mathbf{1}}\right)$ in VGX mice pretreated with vehicle

1367 (VGX/Veh+GBR) or AM6545 (VGX/AM6545+GBR). GBR-induced locomotor activity

1368 (E) and cumulative locomotor response $\left(\mathbf{E}^{\mathbf{1}}\right)$ in mice pretreated with oral gavage of 1369 vehicle (Veh (po)+GBR) or AM6545 (AM6545 (po)+GBR). (F) Expression of 1370 GCaMP6f in VTA dopamine neurons of virally injected Drd2-Cre mice. Please, note 1371 colocalization with TH and GCaMP6f-positive terminals in the striatum and NAc. (G) 1372 Behavioral paradigms used to trigger the activity of VTA dopamine neurons: 1373 exposure to a new environment (new cage) and tail suspension. $(\mathbf{H})$ Temporal 1374 dynamics of DA-neurons activity during the exposure to a new environment (new 1375 cage). Statistics: ${ }^{* *} \mathrm{p}<0.01$ AM6545 vs Veh. (I) Temporal dynamics of DA-neurons 1376 activity during the tail suspension test. Statistics: ${ }^{* *} p<0.01$ AM6545 vs Veh. For number of mice/group and statistical details see Suppl. Table 1.

1378

Supplemental Figure 1: Adaptations to time-locked palatable feeding. (A) Binge consumption and (B) time to first lick during the last BE session of milkshake (lipids+sucrose), sucralose $(2 \mathrm{mM})$ and saccharin $(0.1 \% \mathrm{w} / \mathrm{v})$. Statistics: ${ }^{* *} \mathrm{p}<0.001$ Sucralose or Saccharin vs Milkshake (Lipids/Sucrose). Body composition [fat mass, (C) and lean mass (D)] of control and bingeing mice. (E) Longitudinal profile of the fatty acids oxidation (FAO) from indirect calorimetry measurements (average of 3 consecutive days). For number of mice/group and statistical details see Suppl. Table 1.

Supplemental Figure 2: Peripheral CB1R and vagal afferents. (A) Longitudinal measurement of fatty acid oxidation (FAO) following oral administration of AM6545 $(10 \mathrm{mg} / \mathrm{kg})$. Note no modification in FAO. (B, C) Expression of Cnr1 in sensory vagal neurons labeled from microinjections in the distal and large intestines. For number of mice/group and statistical details see Suppl. Table 1.

Supplemental Figure 3: Homeostatic adaptations in sham and VGX mice during time-locked palatable feeding. (A) 24 hours measurement of chow food intake in sham and VGX bingeing mice. Statistics: ${ }^{* *} p<0.001$ VGX+Binge vs Sham+Binge.

1397 (B) Body weight of both experimental groups. (C-E) Respiratory exchange ratio 1398 (RER), fatty acids oxidation (FAO) and energy expenditure (EE) in sham and VGX 
1399 mice during a binge session. Statistics: ${ }^{*} p<0.05,{ }^{* *} p<0.01$ VGX+Binge vs 1400 Sham+Binge. For number of mice/group and statistical details see Suppl. Table 1.

1401

1402 Supplemental Figure 4: In vivo recoding of $\mathrm{Ca}^{2+}$ transients in VTA dopamine 1403 neurons of Drd2-Cre mice. (A) $\mathrm{Ca}^{2+}$ transients evoked following presentation of a 1404 high-fat high-sugar (HFHS) pellet (positive and reinforcing stimulus). Statistics: 1405 ${ }^{* * *} \mathrm{p}<0.001 \mathrm{HFHS}_{\text {after }}$ vs HFHS before. (B) $\mathrm{Ca}^{2+}$ transients evoked following scruff

1406 restraint (negative stimulus). Note: artefact signals while restraining the mouse were 1407 not included in the analysis. Statistics: ${ }^{* * *} p<0.001$ Scruff ${ }_{\text {after }}$ vs Scruff before. For 1408 number of mice/group and statistical details see Suppl. Table 1. 


\section{Graphical Abstract Berland et al.,}

bioRxiv preprint doi: https://doi.org/10.1101/2020.11.14.382291; this version posted November 16, 2020. The copyright holder for this preprint (which was not certified by peer review) is the authorffunder, who has granted bioRxiv a license to display the preprint in perpetuity. It is made

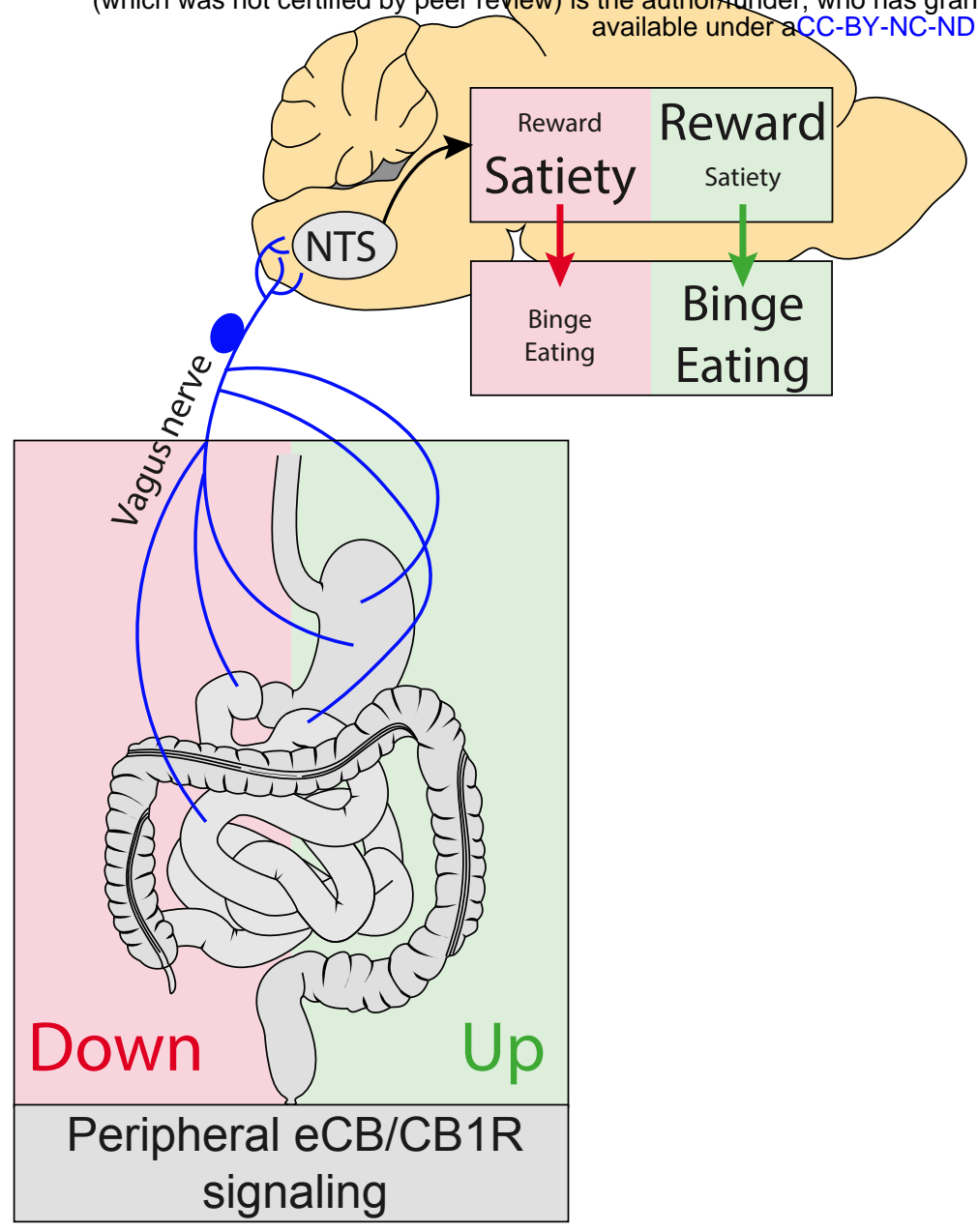


Figure 2 Berland et al.,

bioRxiv preprint doi: https://doi.org/10.1101/2020.11.14.382291; this version posted November 16, 2020. The copyright holder for this preprint (which was not certified by peer review) is the author/funder, who has granted bioRxiv a license to display the preprint in perpetuity. It is made
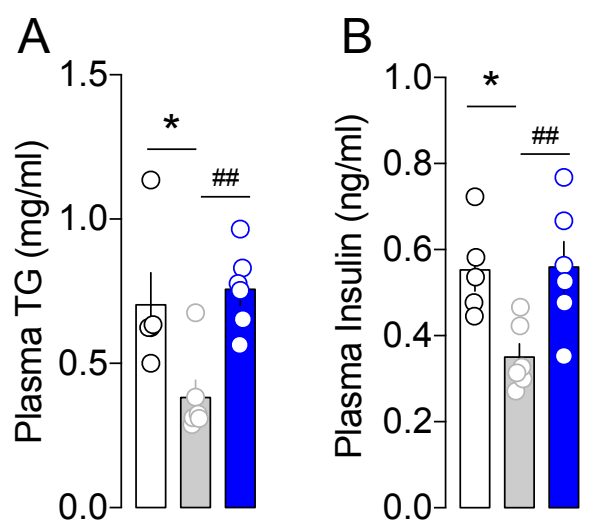
available under aCC-BY-NC-ND 4.0 International license.

$\square$ Control $\square$ Anticipation

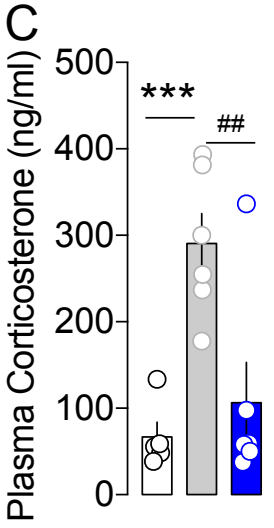

Comsumption
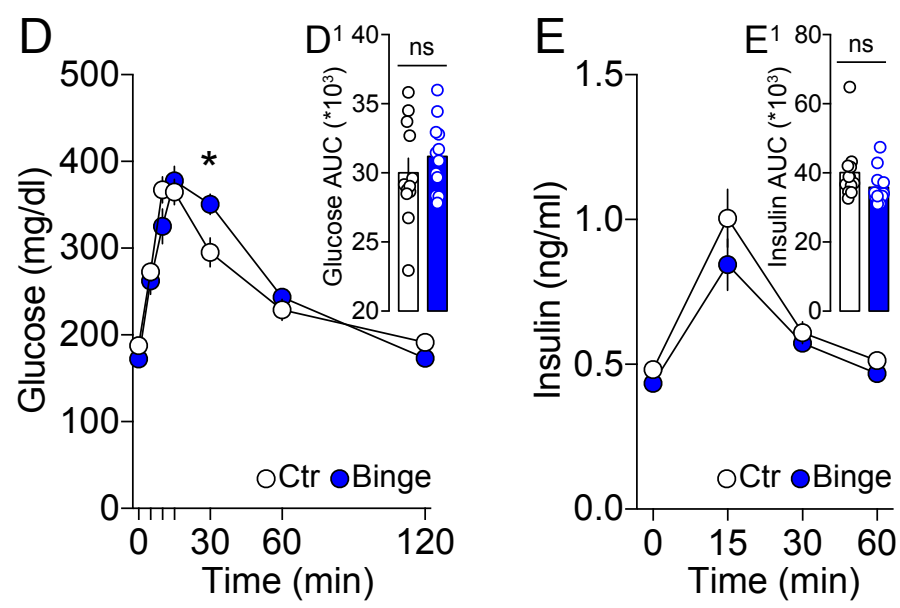


\section{Figure 3 Berland et al.,}

bioRxiv preprint doi: https://doi.org/10.1101/2020.11.14.382291; this version posted November 16, 2020. The copyright holder for this preprint (which was not certified by peer review) is the author/funder, who has granted bioRxiv a license to display the preprint in perpetuity. It is made A available under aCC-BY-NC-ND 4.0 International license.
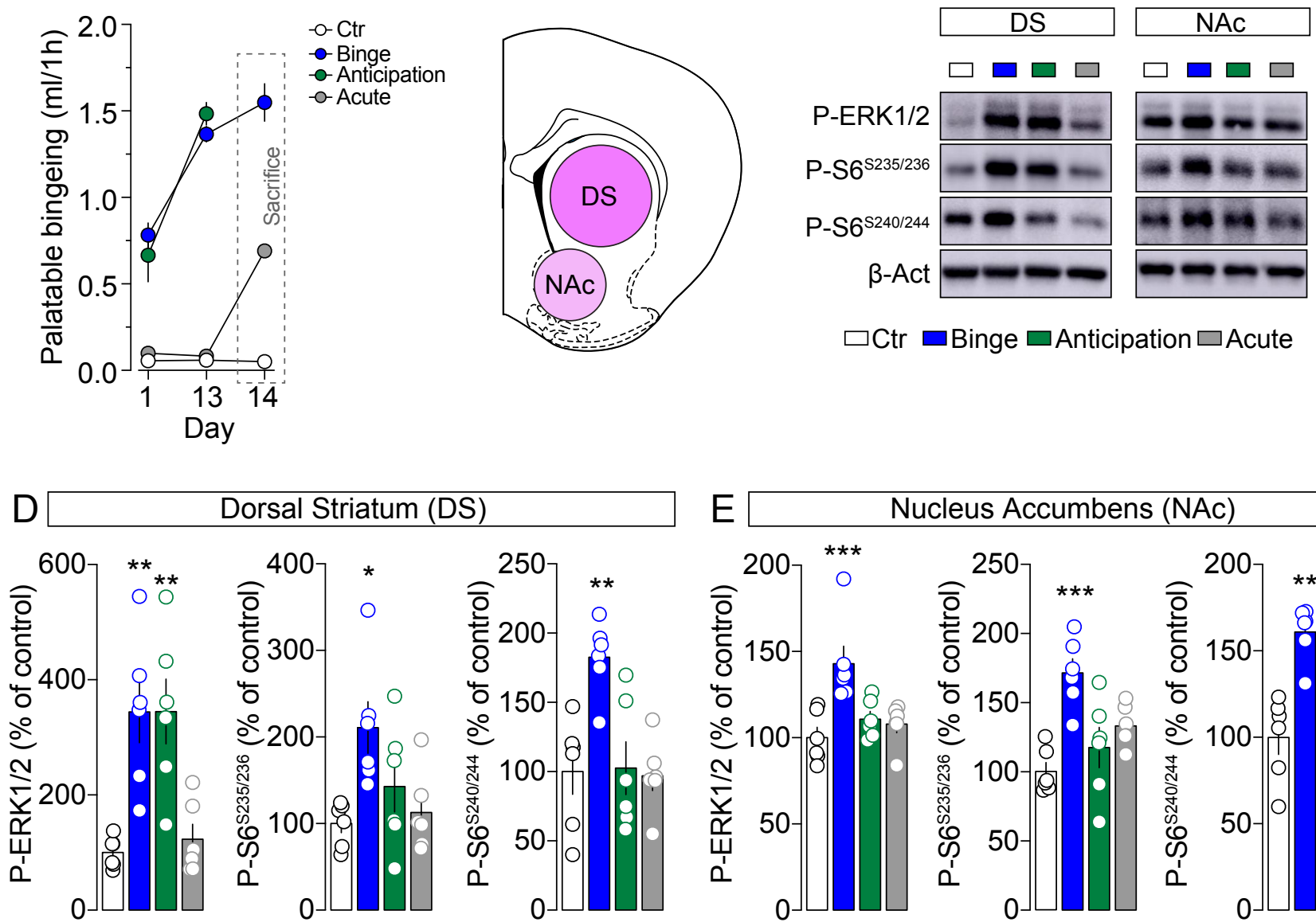

Dorsal Striatum (DS)

E
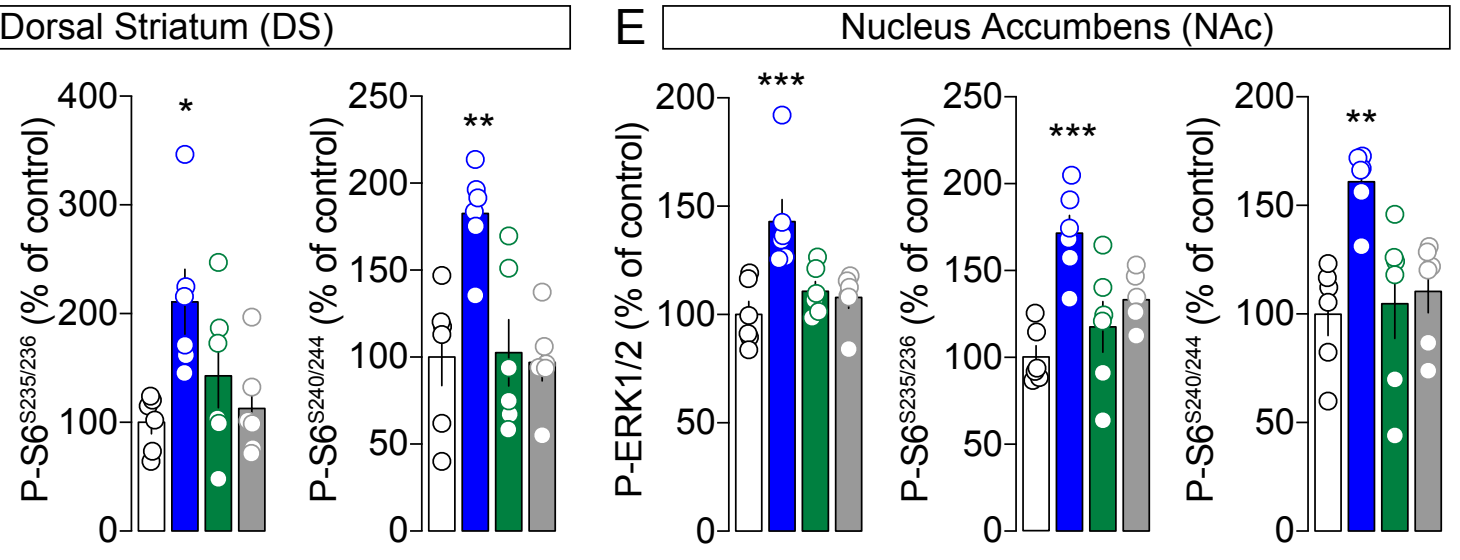

$\square \mathrm{Ctr}$

Binge

Anticipation $\square$ Acute
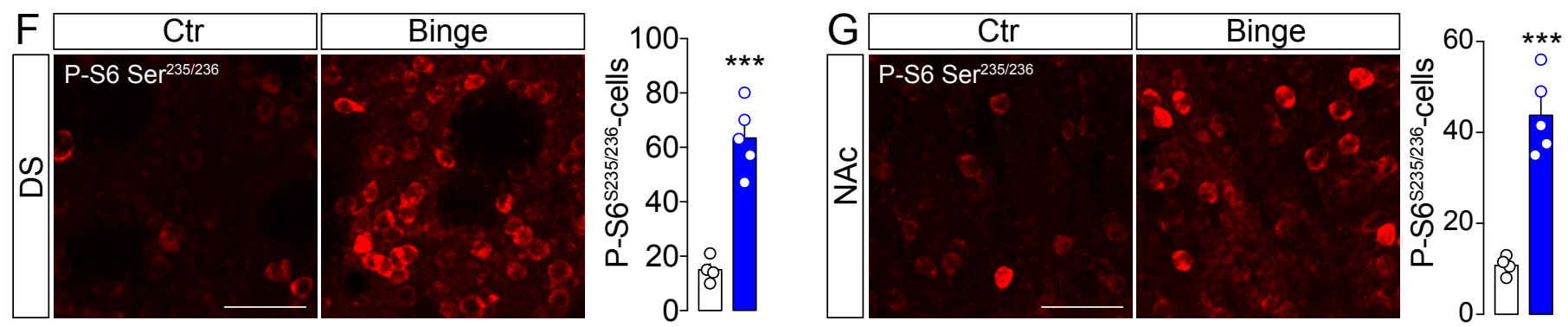


\section{Figure 4 Berland et al.,}
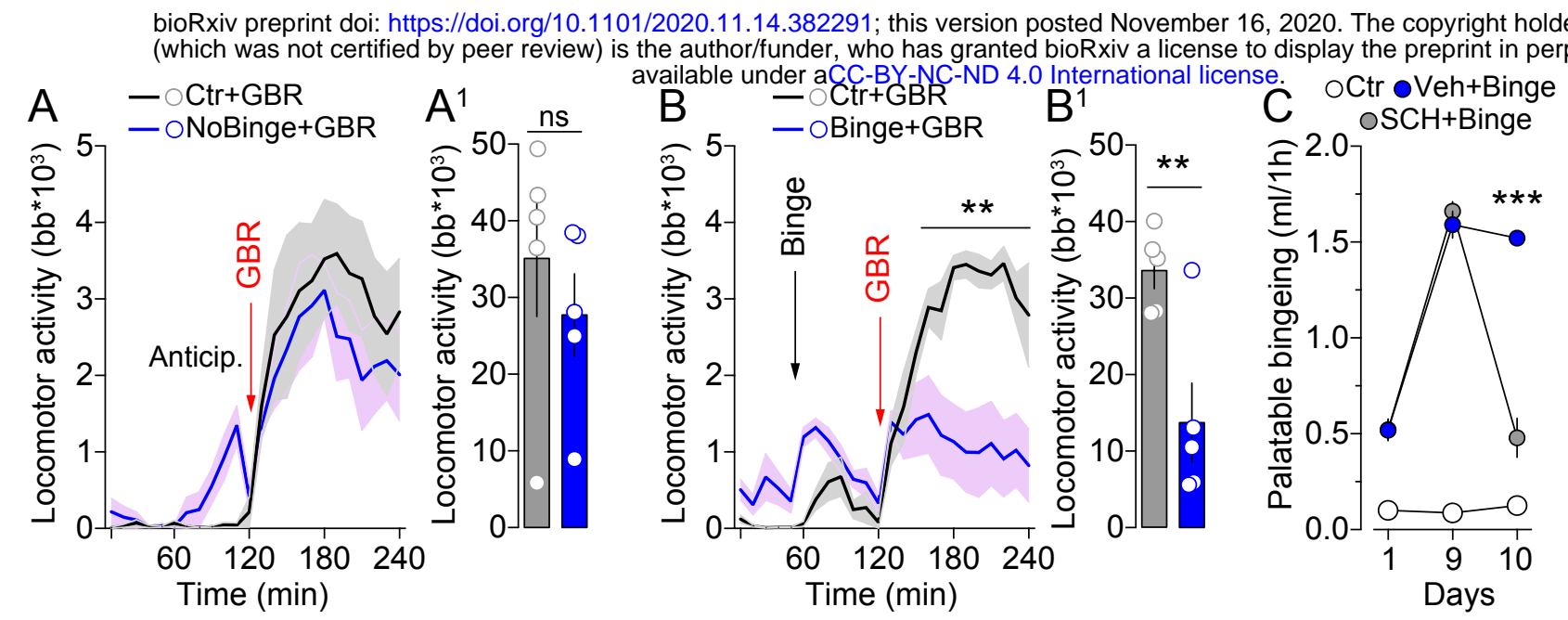

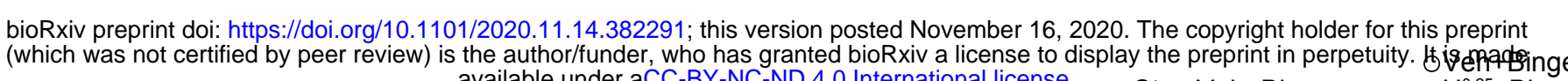

D $\mathrm{H}^{0.25}+\mathrm{Binge}$

E
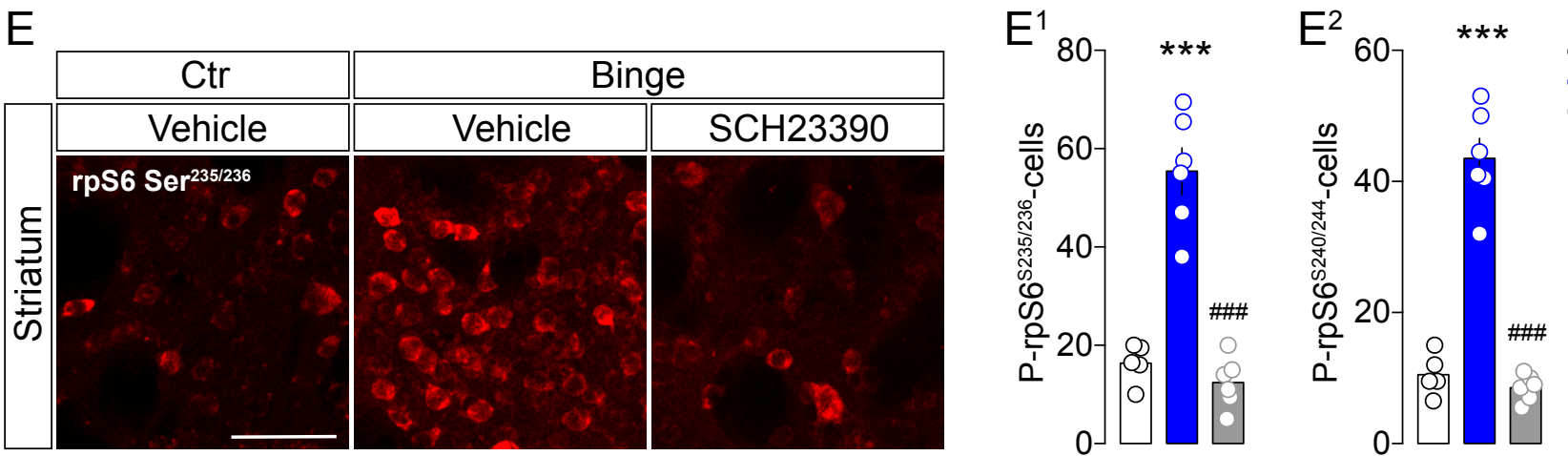

F

$\mathrm{F}^{1}$
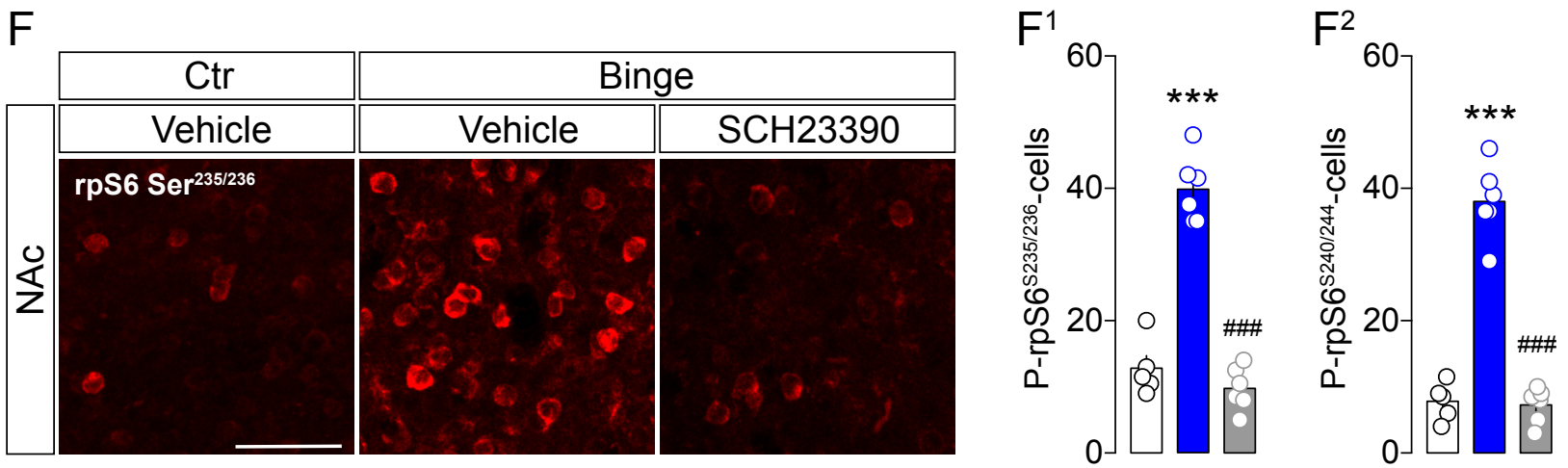

OVeh+Ctr

oVeh+Binge

SCH+Binge
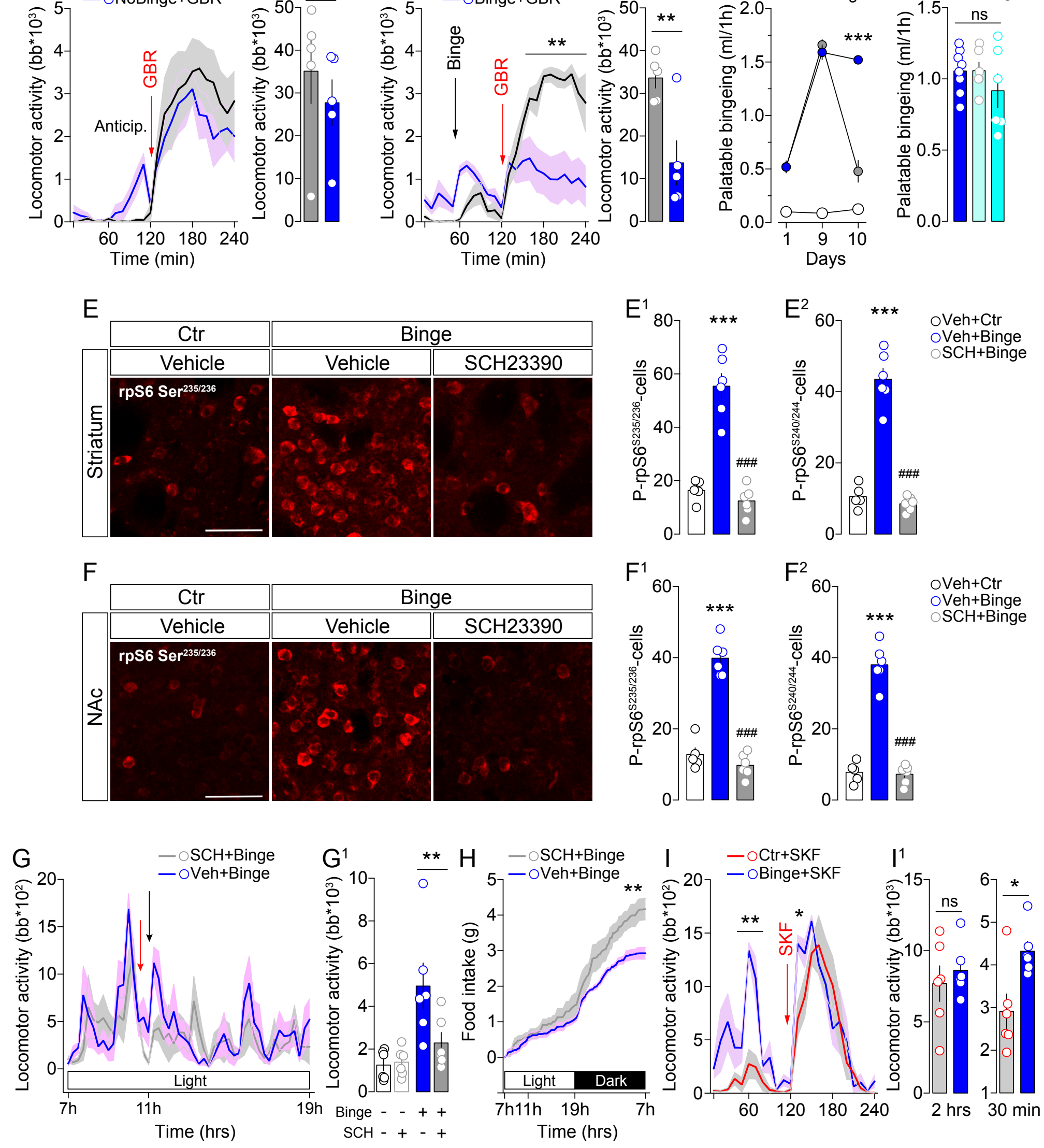


\section{Figure 5 Berland et al.,}
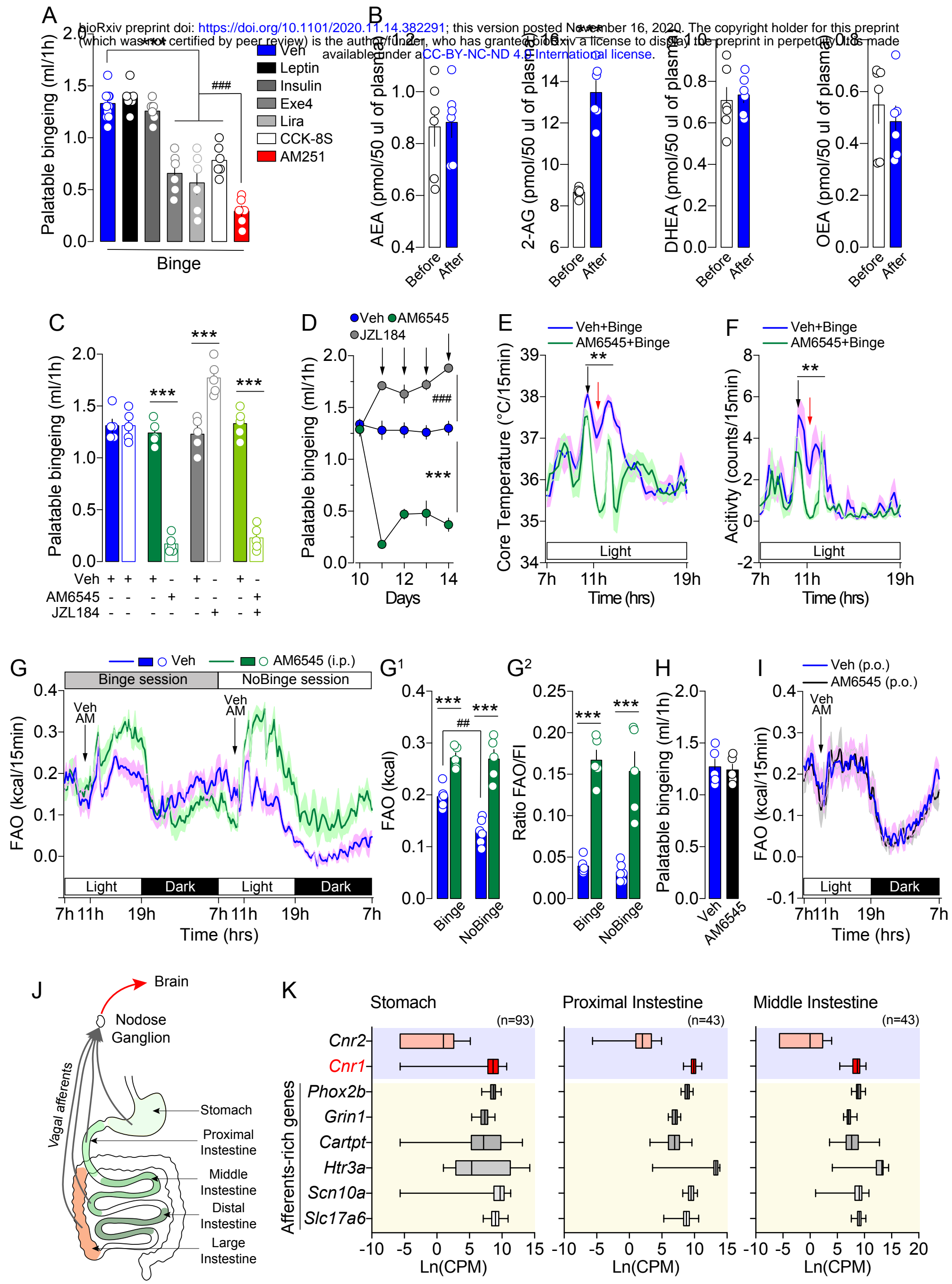

Middle Instestine

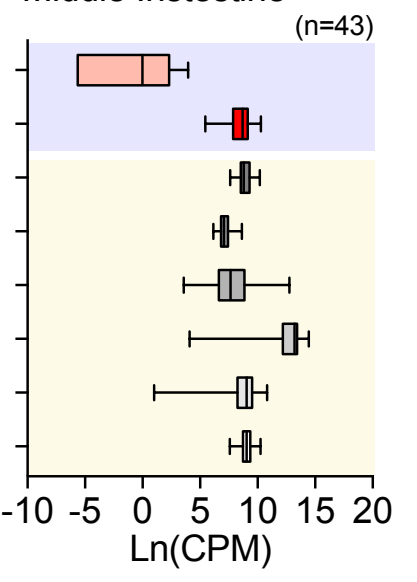


Figure 6 Berland et al.,
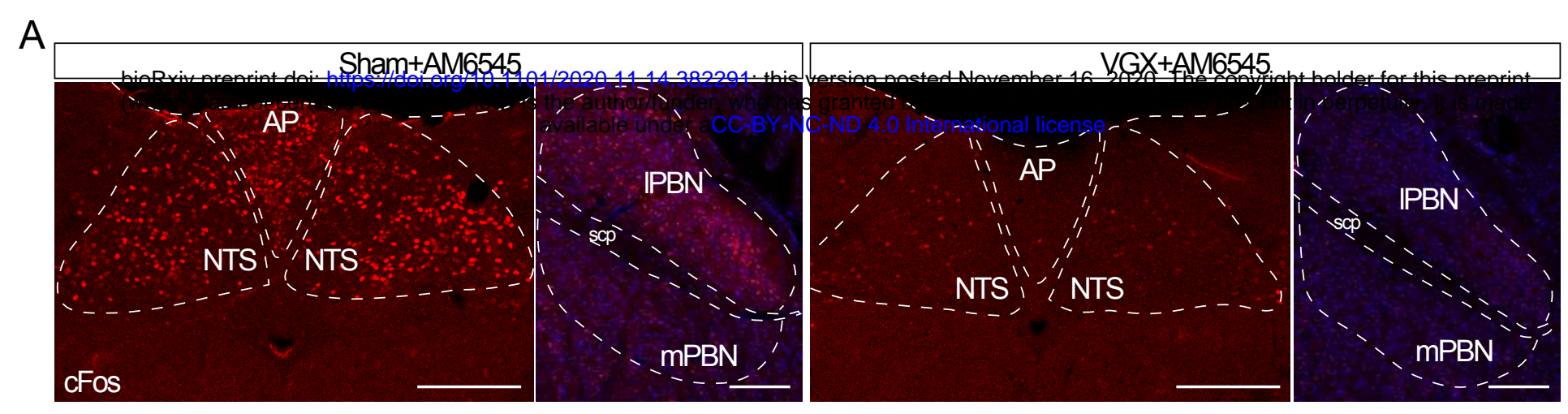

$A^{1}$
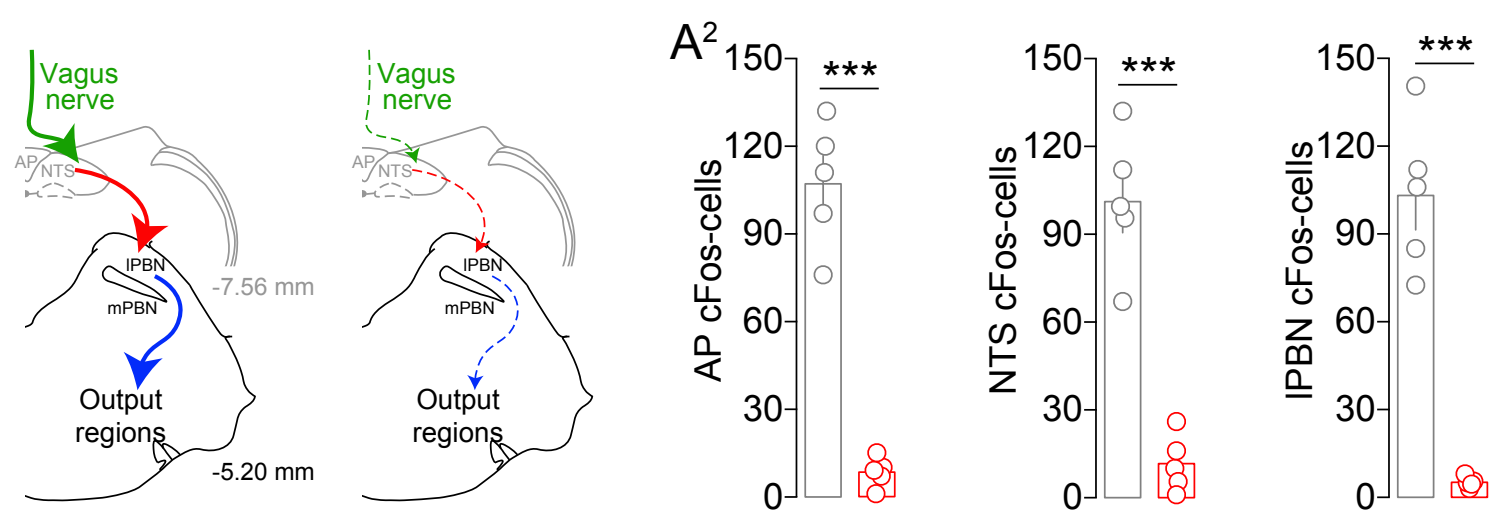

Sham+AM6545 oVGX+AM6545
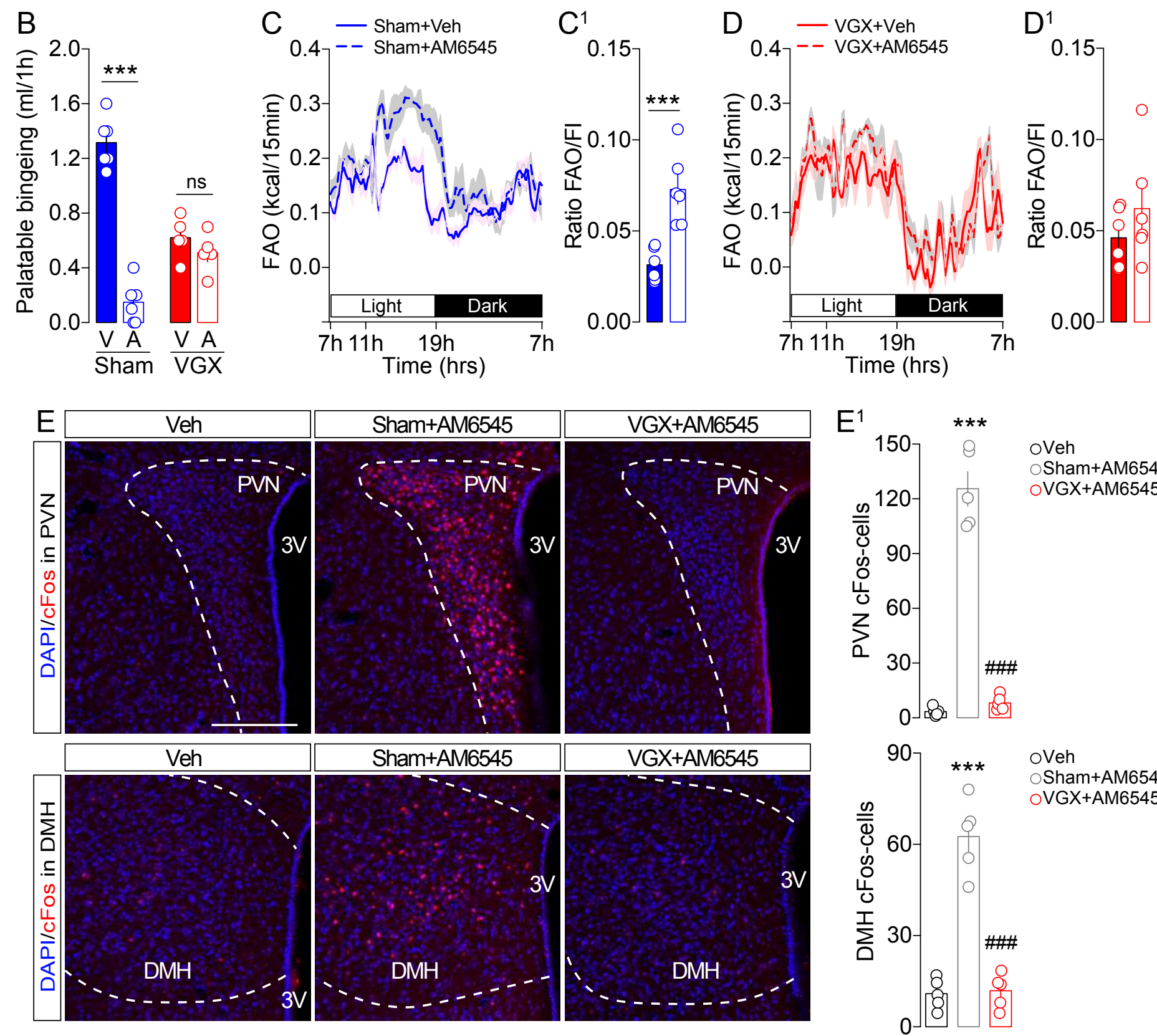

OVeh

Sham+AM6545

oVGX+AM6545

\#

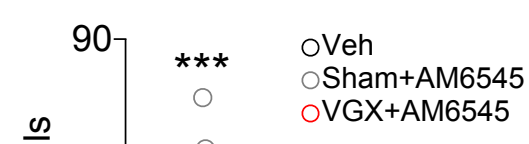




\section{Figure 7 Berland et al.,}

A bioR OVeh+GBR 5 (which was not certifed by peer revient) is the author/funder, whobas.
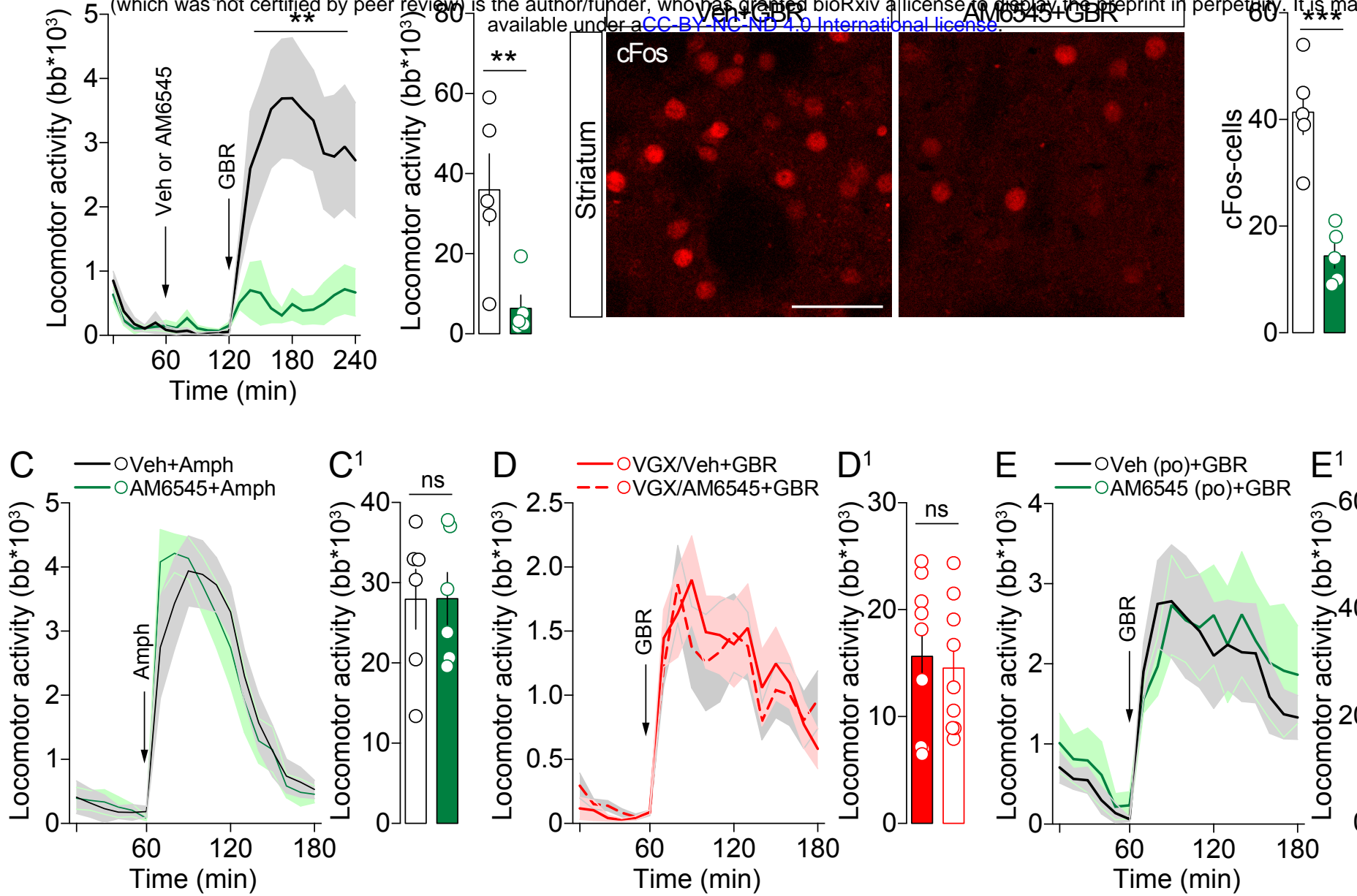

F

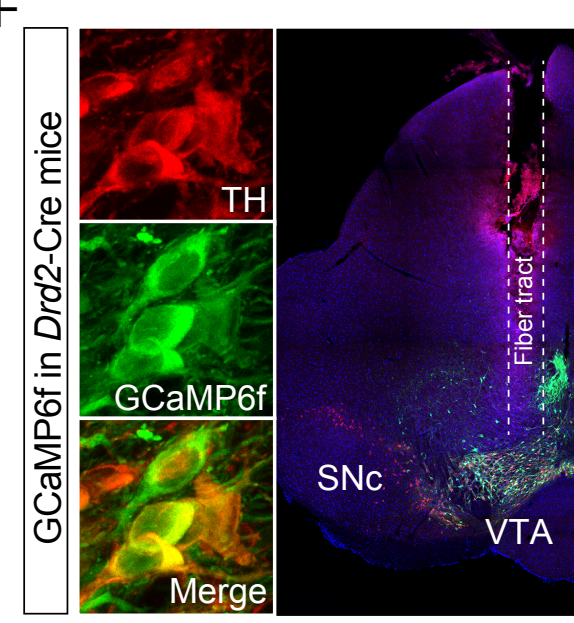

$\mathrm{H}$

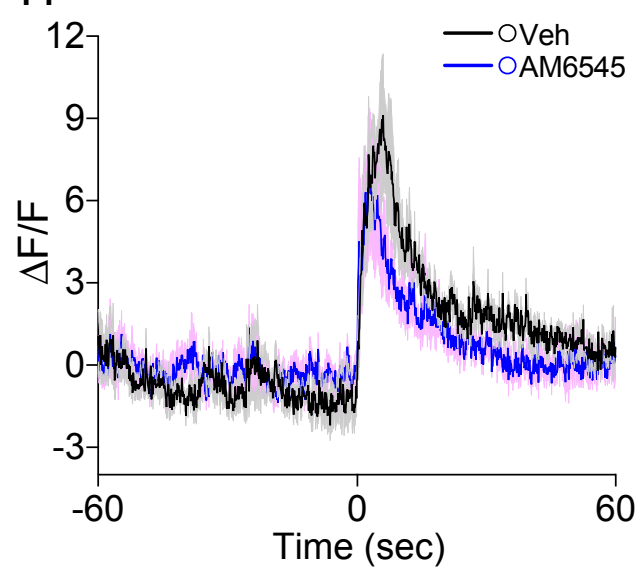

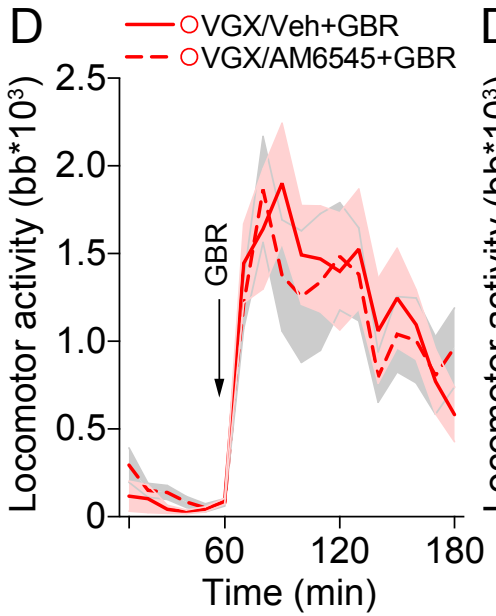

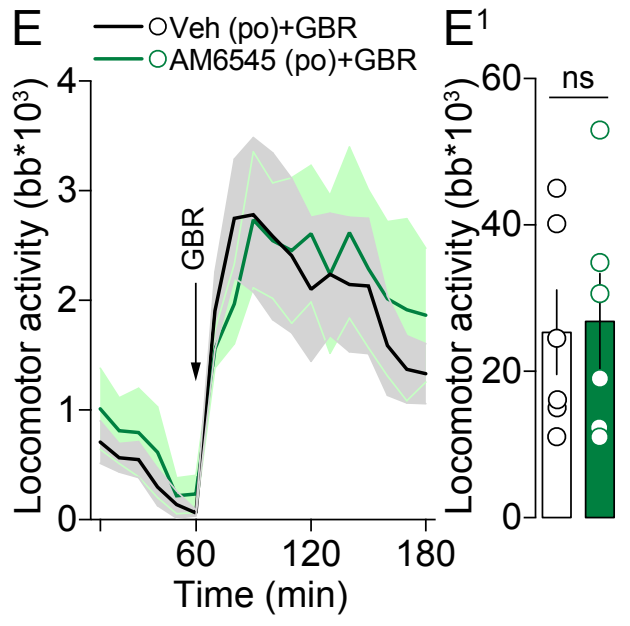

G
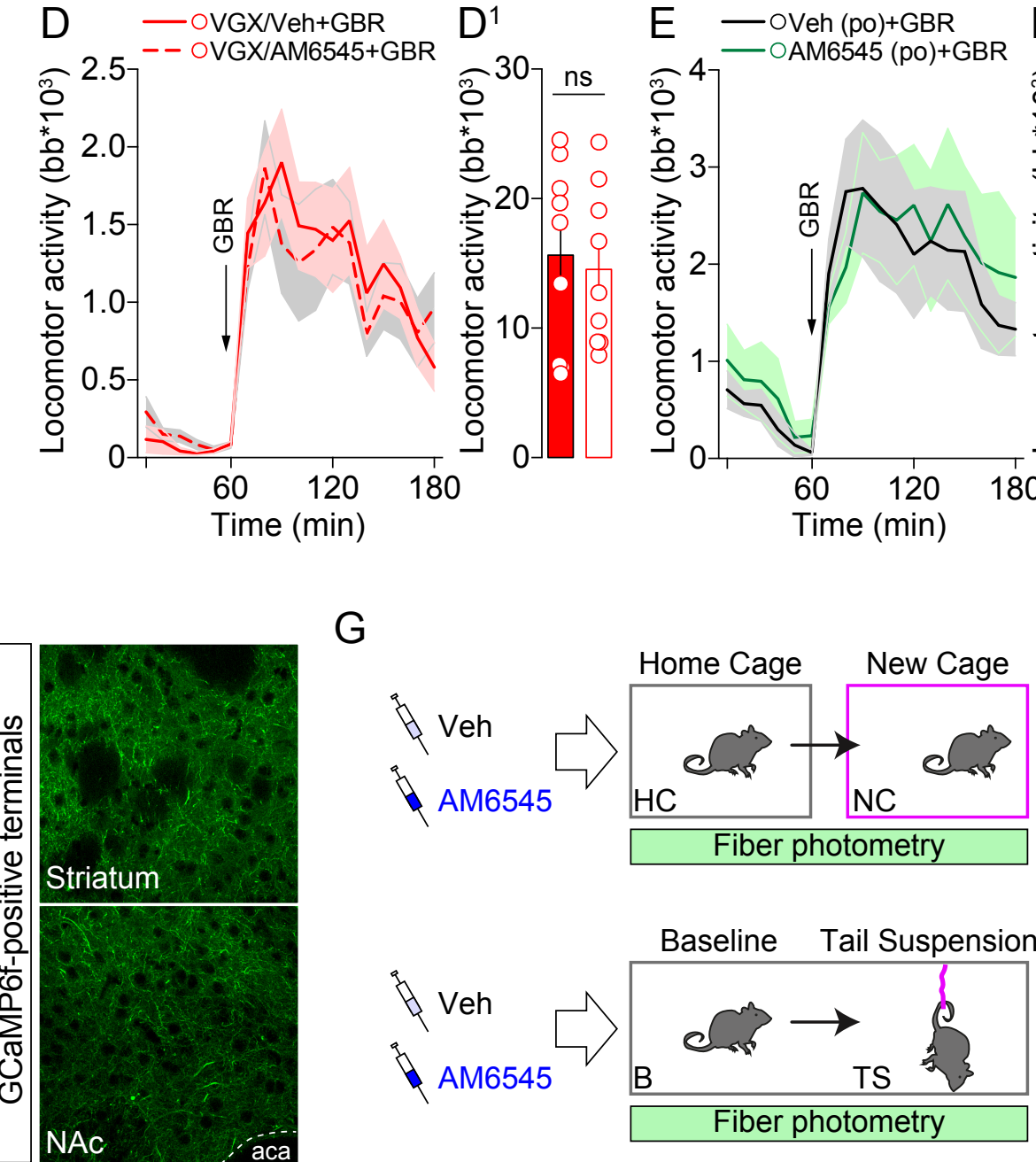
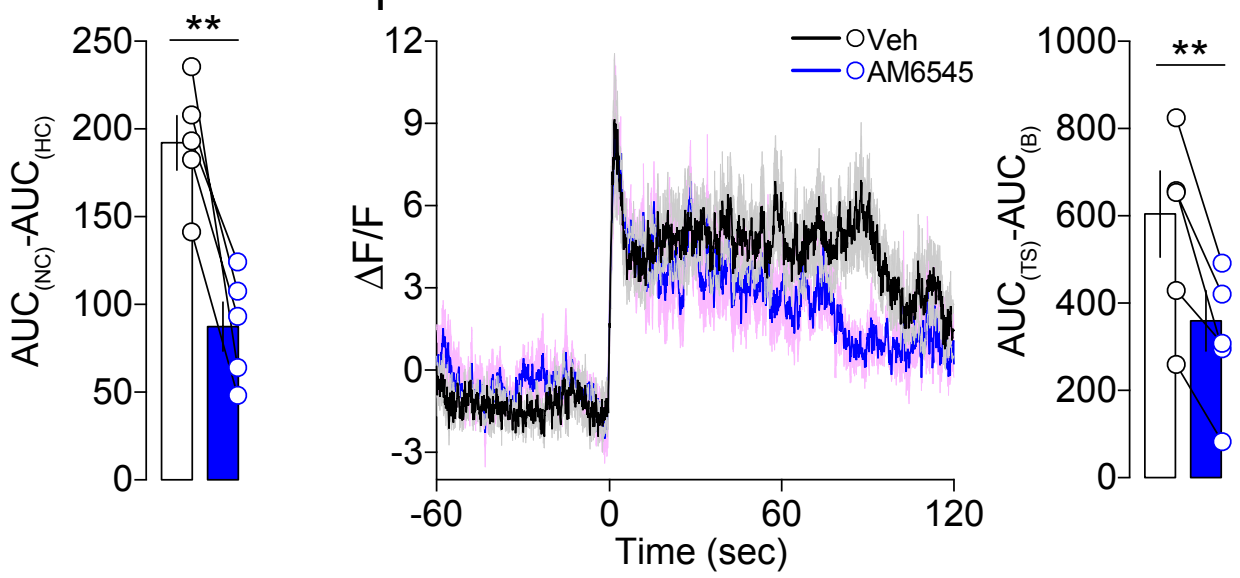


\section{Suppl. Figure 1 Berland et al.,}

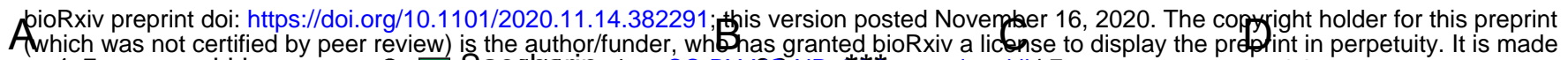
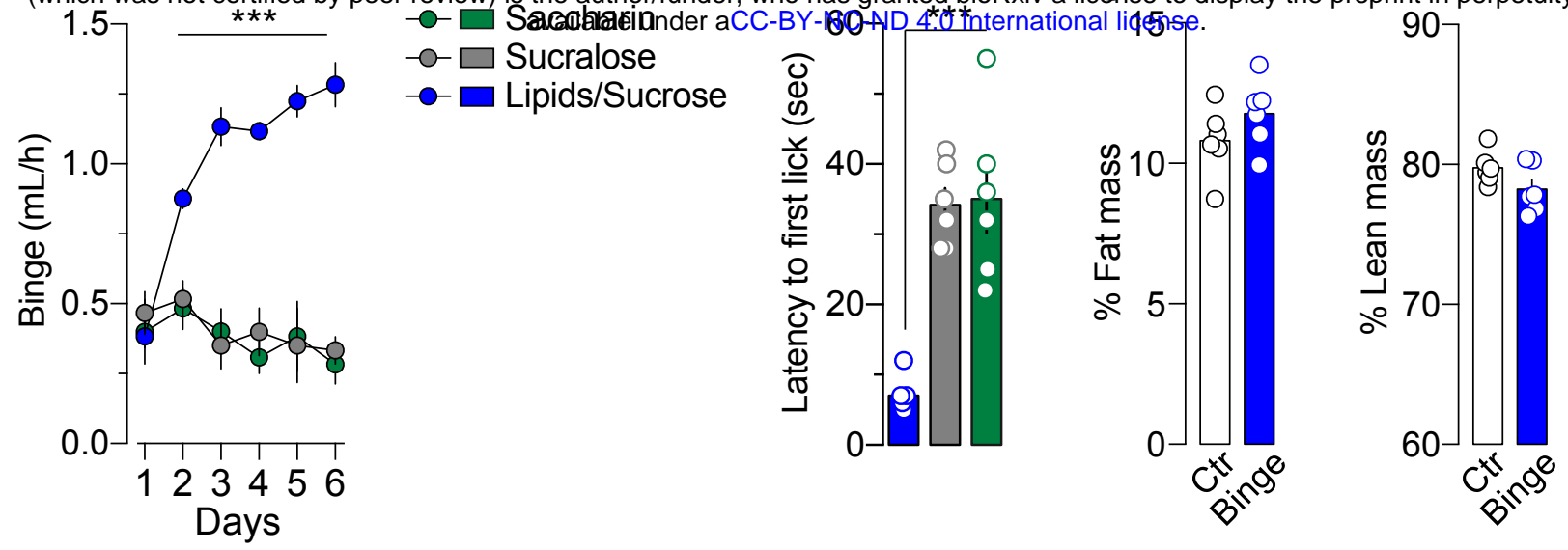

E

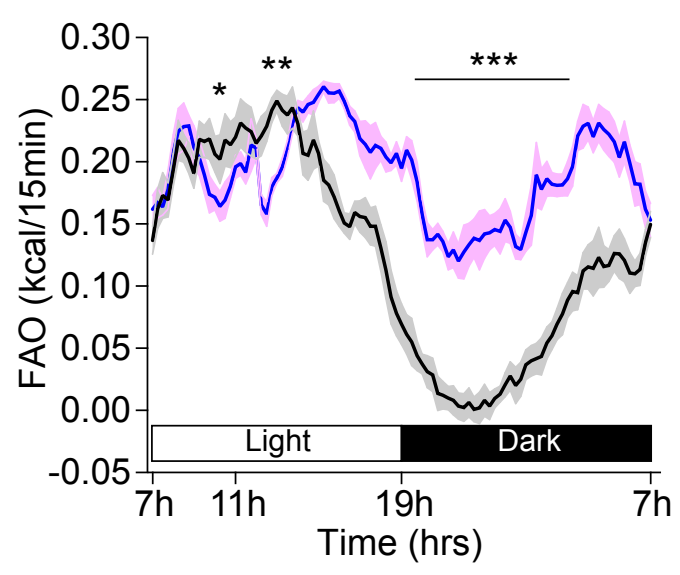

F

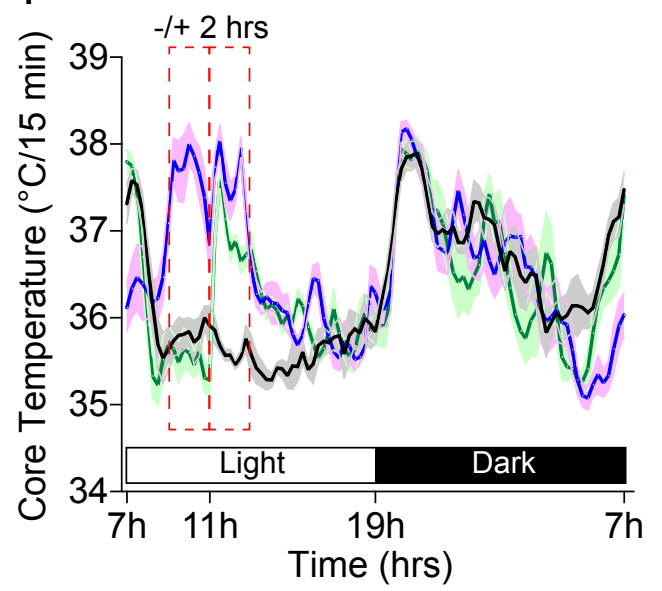

$\mathrm{F}^{1}$

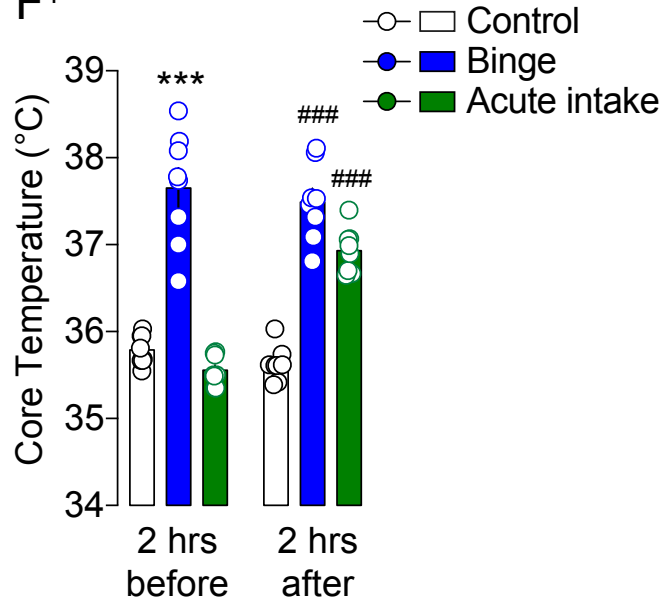




\section{Suppl. Figure 2 Berland et al.,}

bioRxiv preprint doi: https://doi.org/10.1101/2020.11.14.382291; this version posted November 16, 2020. The copyright holder for this preprint (which was not certified by peer review) is the author/funder, who has granted bioRxiv a license to display the preprint in perpetuity. It is made

A

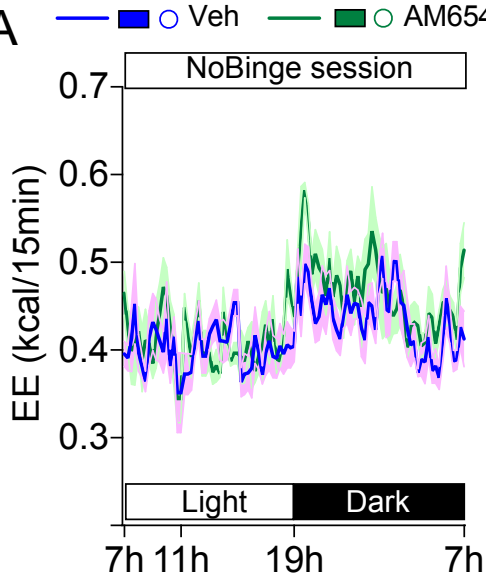

B

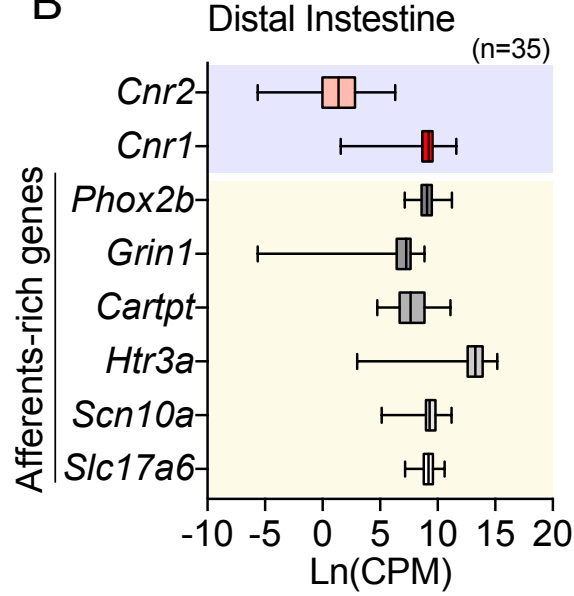

C

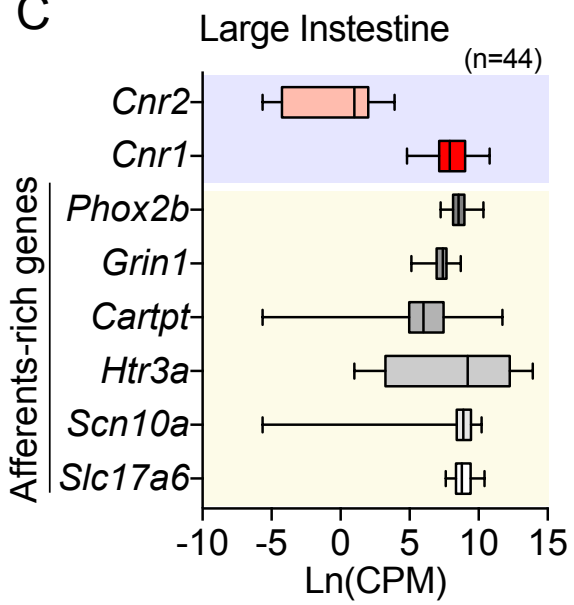




\section{Suppl. Figure 3 Berland et al.,}

bioRxiv preprint doi: https://doi.org/10.1101/2020.11.14.382291; this version posted November 16, 2020. The copyright holder for this preprint (which was not certified by peer review) is the author/funder, who has granted bioRxiv a license to display the preprint in perpetuity. It is made
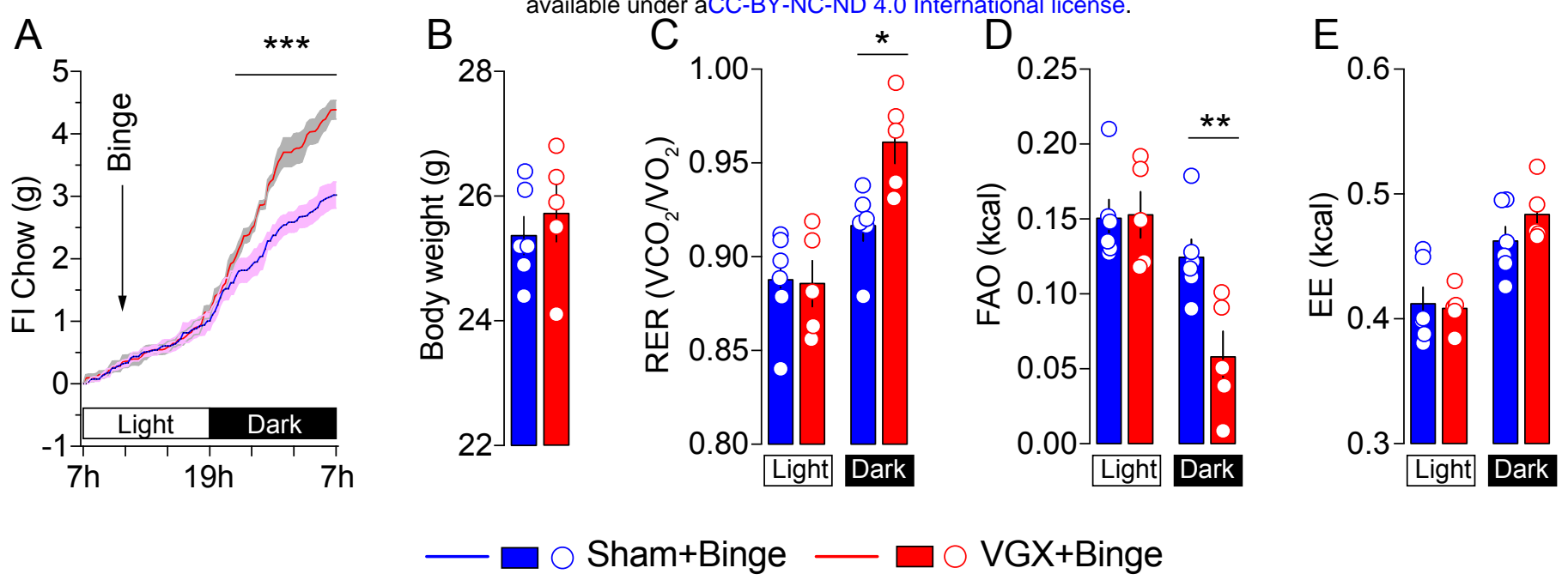


\section{Suppl. Figure 3 Berland et al.,}

bioRxiv preprint doi: https://doi.org/10.1101/2020.11.14.382291; this version posted November 16, 2020. The copyright holder for this preprint

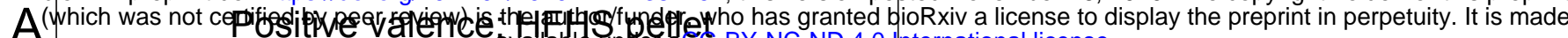
A

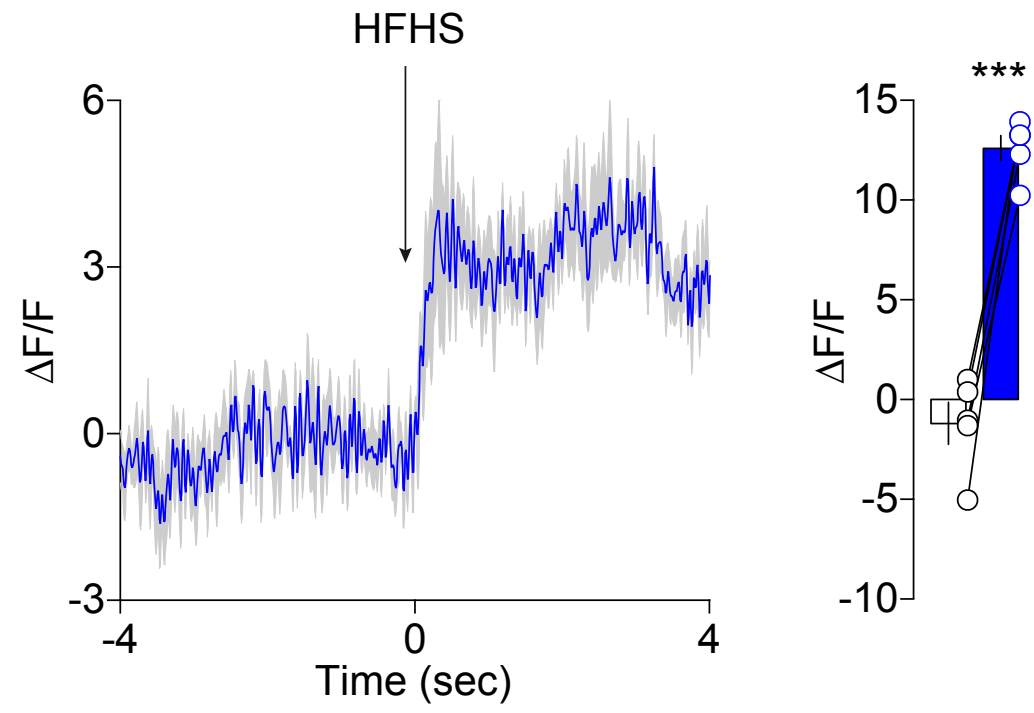

$\mathrm{B}$

Negative valence: Scruff restraint
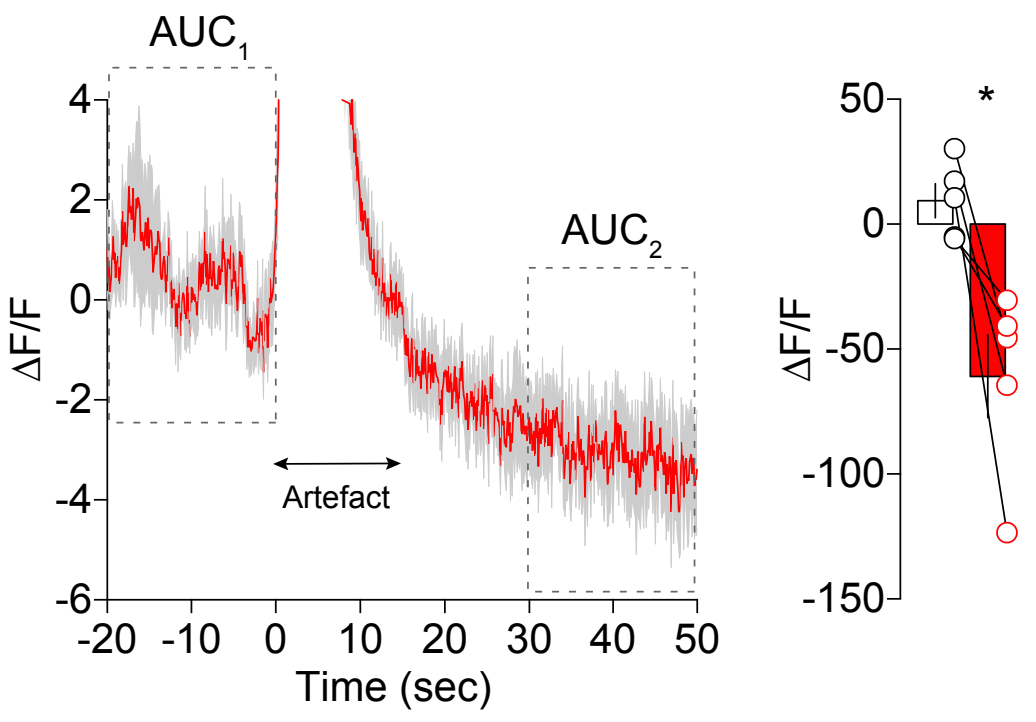